\title{
Characterization of Harmonic Resonances in the Presence of the Steinmetz Circuit in Power Systems
}

\author{
Luis Sainz ${ }^{1}$, Eduardo Caro ${ }^{2}$ and Sara Riera ${ }^{1}$ \\ ${ }^{1}$ Department of Electrical Engineering, ETSEIB-UPC, \\ 2Department of Electrical Engineering, GSEE-UCLM, \\ Spain
}

\section{Introduction}

An electric power system is expected to operate under balanced three-phase conditions; however, single-phase loads such as traction systems can be connected, leading to unbalanced line currents. These systems are single-phase, non-linear, time-varying loads closely connected to the utility power supply system. Among problems associated with them, special consideration must be given to the presence of unbalanced and distorted currents (Barnes \& Wong, 1991; Capasso, 1998; Hill, 1994; Howroyd, 1989; Marczewski, 1999; Qingzhu et al., 2010a, 2010b). These operating conditions damage power quality, producing undesirable effects on networks and affecting the correct electric system operation (Arendse \& Atkinson-Hope, 2010; Chen, 1994; Chen \& Kuo, 1995; Chindris et. al., 2002; Lee \& Wu, 1993; Mayer \& Kropik, 2005). The unbalanced currents cause unequal voltage drops in distribution lines, resulting in load bus voltage asymmetries and unbalances (Chen, 1994; Qingzhu et al., 2010a, 2010b). For this reason, several methods have been developed to reduce unbalance in traction systems and avoid voltage asymmetries, for example feeding railroad substations at different phases alternatively, and connecting special transformers (e.g. Scott connection), Static Var Compensators (SVCs) or external balancing equipment (ABB Power Transmission, n.d.; Chen, 1994; Chen \& Kuo, 1995; Hill, 1994; Lee \& Wu, 1993; Qingzhu et al., 2010a, 2010b). The last method, which is incidentally not the most common, consists of suitably connecting reactances (usually an inductor and a capacitor in delta configuration) with the single-phase load representing the railroad substation (Barnes \& Wong, 1991; Qingzhu et al., 2010a, 2010b). This method is also used with industrial high-power single-phase loads and electrothermal appliances (Chicco et al., 2009; Chindris et. al., 2002; Mayer \& Kropik, 2005).

This delta-connected set, more commonly known as Steinmetz circuit, (Barnes \& Wong, 1991; Jordi et al., 2002; Mayer \& Kropik, 2005), allows the network to be loaded with symmetrical currents. Several studies on Steinmetz circuit design under sinusoidal balanced or unbalanced conditions aim to determine the reactance values to symmetrize the currents consumed by the single-phase load. Some works propose analytical expressions and optimization techniques for Steinmetz circuit characterization, (Arendse \& Atkinson-Hope, 2010; Jordi et. al, 2002; Mayer \& Kropik, 2005; Qingzhu et al., 2010a, 2010b; Sainz \& Riera, 
submitted for publication). In general, the values of the symmetrizing elements should vary in order to compensate for the usual single-phase load fluctuations. Unfortunately, the typical inductances and capacitors have fixed values. However, this can be solved by the introduction of thyristor-controlled reactive elements due to the development of power electronics in the last few years and the use of step variable capacitor banks, (Barnes \& Wong, 1991; Chindris et al., 2002).

Steinmetz circuit design must consider circuit performance and behavior under nonsinusoidal conditions because of the growing presence of non-linear devices in electric power systems in the last few decades, (Arendse \& Atkinson-Hope, 2010; Chicco et al., 2009; Czarnecki, 1989, 1992). Harmonic currents injected by non-linear devices can cause voltage distortions, which may damage power quality. In this sense, the effects of harmonics on power systems and their acceptable limits are well known [IEC power quality standards, (IEC 6100-36, 2008); Task force on Harmonic Modeling and Simulation, 1996, 2002]. In the above conditions, the parallel and series resonance occurring between the Steinmetz circuit capacitor and the system inductors must be located to prevent harmonic problems when the Steinmetz circuit is connected. The parallel resonance occurring between the Steinmetz circuit capacitor and the supply system inductors is widely studied in (Caro et al., 2006; Sainz et al., 2004, 2005, 2007). This resonance can increase harmonic voltage distortion in the presence of non-linear loads injecting harmonic currents into the system. The problem is pointed out in (Sainz et al., 2004). In (Caro et al., 2006; Sainz et al., 2005), it is numerically and analytically characterized, respectively. In (Sainz et al., 2005), several curves are fitted numerically from the power system harmonic impedances to predict the resonance at the fifth, seventh and eleventh harmonics only. In (Caro et al., 2006), the resonance is analytically located from the theoretical study of the power system harmonic impedances. Finally, the analytical expressions in (Caro et al., 2006) to predict the parallel resonance frequency are expanded in (Sainz et al., 2007) to consider the influence of the Steinmetz circuit capacitor loss with respect to its design value. The series resonance "observed" from the supply system is also studied and located in (Sainz et al., 2009a, 2009b, in press). This resonance can affect power quality in the presence of a harmonic-polluted power supply system because the consumed harmonic currents due to background voltage distortion can be magnified. It is numerically and analytically studied in (Sainz et al., 2009a, 2009b), respectively. In (Sainz et al., 2009a), graphs to locate the series resonance frequency and the admittance magnitude values at the resonance point are numerically obtained from the power system harmonic admittances. In (Sainz et al., 2009b), analytical expressions to locate the series resonance are obtained from these admittances. Finally, the analytical expressions developed in (Sainz et al., 2009b) to predict resonance frequencies are expanded in (Sainz et al., in press) to consider the influence of Steinmetz circuit capacitor changes with respect to its design value.

This chapter, building on work developed in the previous references, not only summarizes the above research but also unifies the study of both resonances, providing an expression unique to their location. The proposed expression is the same as in the series resonance case, but substantially improves those obtained in the parallel resonance case. Moreover, the previous studies are completed with the analysis of the impact of the Steinmetz circuit inductor resistance on the resonance. This resistance, as well as damping the impedance values, shifts the resonance frequency because it influences Steinmetz circuit design (Sainz \& Riera, submitted for publication). A sensitivity analysis of all variables involved in the location of the parallel and series resonance is also included. The chapter ends with several experimental tests to validate the proposed expression and several examples of its application. 


\section{Balancing ac traction systems with the Steinmetz circuit}

Fig. 1a shows one of the most widely used connection schemes of ac traction systems, where the railroad substation is formed by a single-phase transformer feeding the traction load from the utility power supply system. As the railroad substation is a single-phase load which may lead to unbalanced utility supply voltages, several methods have been proposed to reduce unbalance (Chen, 1994; Hill, 1994), such as feeding railroad substations at different phases alternatively, and using special transformer connections (e.g. Scott-connection), SVCs or external balancing equipment. To simplify the study of these methods, the single-phase transformer is commonly considered ideal and the traction load is represented by its equivalent inductive impedance, $\underline{Z}_{\mathrm{L}}=R_{\mathrm{L}}+j X_{\mathrm{L}}$, obtained from its power demand at the fundamental frequency, Fig. 1b (Arendse \& Atkinson-Hope, 2010; Barnes \& Wong, 1991; Chen, 1994; Mayer \& Kropik, 2005; Qingzhu et al., 2010a, 2010b). According to Fig. 1c, external balancing equipment consists in the delta connection of reactances (usually an inductor $\underline{Z}_{1}$ and a capacitor $\underline{Z}_{2}$ ) with the single-phase load representing the railroad substation in order to load the network with balanced currents. This circuit, which is known as Steinmetz circuit (ABB Power Transmission, n.d.; Barnes \& Wong, 1991; Mayer \& Kropik, 2005), is not the most common balancing method in traction systems but it is also used in industrial high-power single-phase loads and electrothermal appliances (Chicco et al., 2009; Chindris et. al., 2002; Mayer \& Kropik, 2005).

(a)

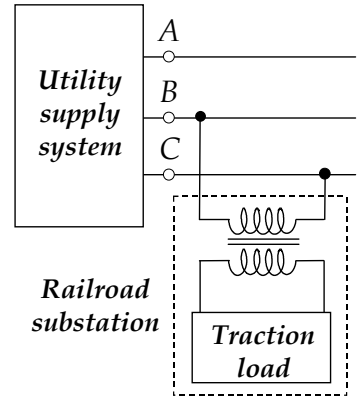

(b)

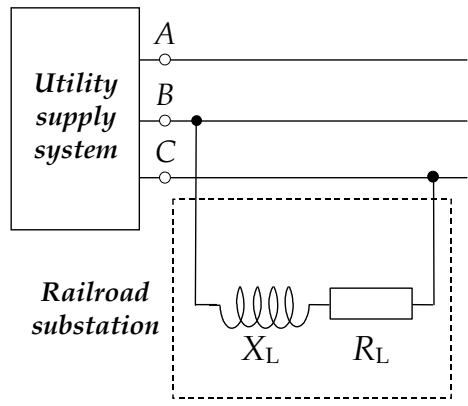

(c)

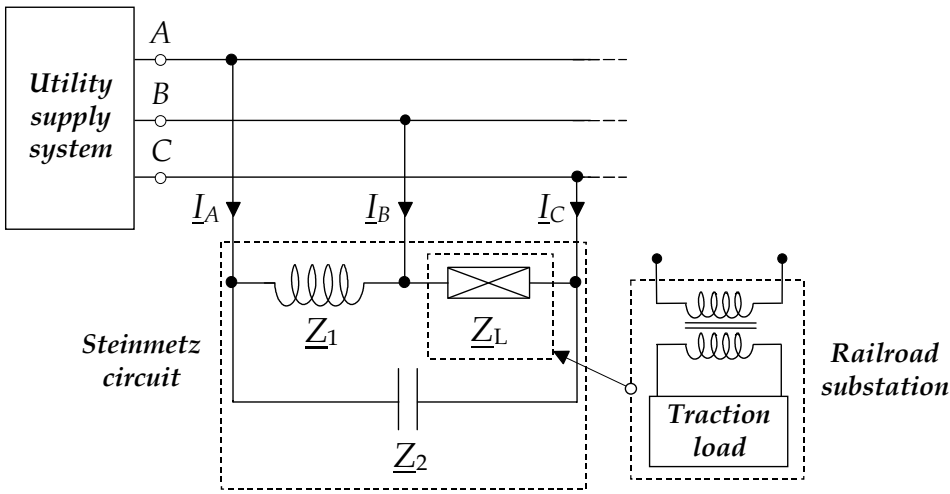

Fig. 1. Studied system: a) Railroad substation connection scheme. b) Simplified railroad substation circuit. c) Steinmetz circuit. 


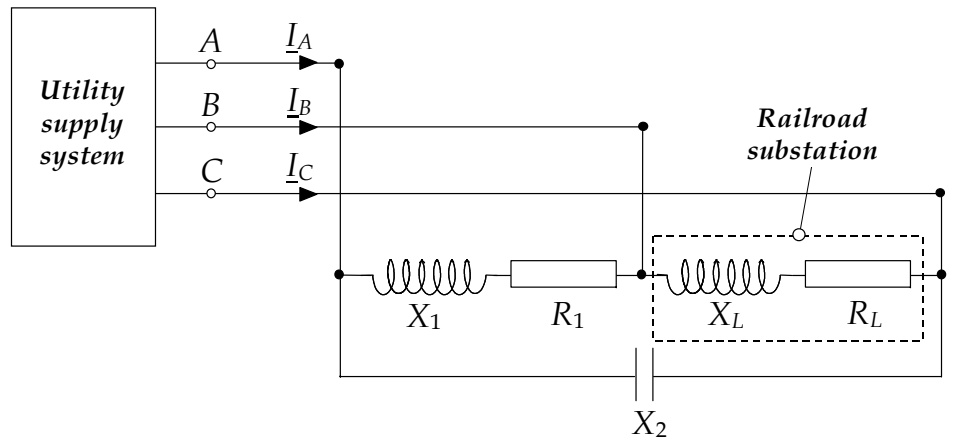

Fig. 2. Detailed Steinmetz circuit.

Fig. 2 shows the Steinmetz circuit in detail. The inductor is represented with its associated resistance, $\underline{Z}_{1}=R_{1}+j X_{1}$, while the capacitor is considered ideal, $\underline{Z}_{2}=-j X_{2}$. Steinmetz circuit design aims to determine the reactances $X_{1}$ and $X_{2}$ to balance the currents consumed by the railroad substation. Thus, the design value of the symmetrizing reactive elements is obtained by forcing the current unbalance factor of the three-phase fundamental currents consumed by the Steinmetz circuit $\left(\underline{I}_{A}, \underline{I}_{B}, \underline{I}_{C}\right)$ to be zero. Balanced supply voltages and the pure Steinmetz circuit inductor (i.e., $R_{1}=0$ ) are usually considered in Steinmetz circuit design, and the values of the reactances can be obtained from the following approximated expressions (Sainz et al., 2005):

$$
X_{1, \text { apr }}\left(R_{L}, \lambda_{L}\right)=\frac{\sqrt{3} R_{L}}{\lambda_{L}^{2}\left(1+\sqrt{3} \tau_{L}\right)} \quad ; \quad X_{2, \text { apr }}\left(R_{L}, \lambda_{L}\right)=\frac{\sqrt{3} R_{L}}{\lambda_{L}^{2}\left(1-\sqrt{3} \tau_{L}\right)},
$$

where

$$
\tau_{L}=\frac{X_{L}}{R_{L}}=\frac{\sqrt{1-\lambda_{L}^{2}}}{\lambda_{L}}
$$

and $\lambda_{L}=R_{L} /\left|\underline{Z}_{L}\right|$ and $\left|\underline{Z}_{L}\right|$ are the displacement power factor and the magnitude of the single-phase load at fundamental frequency, respectively.

In (Mayer \& Kropik, 2005), the resistance of the Steinmetz inductor is considered and the symmetrizing reactance values are obtained by optimization methods. However, no analytical expressions for the reactances are provided. In (Sainz \& Riera, submitted for publication), the following analytical expressions have recently been deduced

$$
X_{1}\left(R_{L}, \lambda_{L}, \tau_{1}\right)=\frac{R_{L} \lambda_{1}^{2}\left(\sqrt{3}-\tau_{1}\right)}{\lambda_{L}^{2} \tau_{1}^{2}\left(1+\sqrt{3} \tau_{L}\right)} \quad ; \quad X_{2}\left(R_{L}, \lambda_{L}, \tau_{1}\right)=\frac{R_{L}\left(\sqrt{3}-\tau_{1}\right)}{\lambda_{L}^{2}\left\{\left(1-\sqrt{3} \tau_{L}\right)-\tau_{1}\left(\sqrt{3}+\tau_{L}\right)\right\}},
$$

where $\tau_{1}=R_{1} / X_{1}=\lambda_{1} /\left(1-\lambda_{1}^{2}\right)^{1 / 2}$ is the $\mathrm{R} / \mathrm{X}$ ratio of the Steinmetz circuit inductor, and $\lambda_{1}=R_{1} /\left|\underline{Z}_{1}\right|$ and $\left|\underline{Z}_{1}\right|$ are the displacement power factor and the magnitude of the Steinmetz circuit inductor at the fundamental frequency, respectively. It must be noted that (1) can be derived from (3) by imposing $\tau_{1}=0$ (and therefore $\lambda_{1} / \tau_{1}=1$ ). The Steinmetz 
circuit under study (with an inductor $X_{1}$ and a capacitor $X_{2}$ ) turns out to be possible only when $X_{1}$ and $X_{2}$ values are positive. Thus, according to (Sainz \& Riera, submitted for publication), $X_{1}$ is always positive while $X_{2}$ is only positive when the displacement power factor of the single-phase load satisfies the condition

$$
1 \geq \lambda_{\mathrm{L}} \geq \lambda_{\mathrm{LC}}=\frac{\tau_{1}+\sqrt{3}}{2 \sqrt{1+\tau_{1}^{2}}},
$$

where the typical limit $\lambda_{L C}=(\sqrt{ } 3) / 2$ can be obtained from (4) by imposing $\tau_{1}=0$ (Jordi et al., 2002; Sainz \& Riera, submitted for publication).

Supply voltage unbalance is considered in (Qingzhu et al., 2010a, 2010b) by applying optimization techniques for Steinmetz circuit design, and in (Jordi et al., 2002; Sainz \& Riera, submitted for publication) by obtaining analytical expressions for the symmetrizing reactances. However, the supply voltage balance hypothesis is not as critical as the pure Steinmetz circuit inductor hypothesis. Harmonics are not considered in the literature in Steinmetz circuit design and the reactances are determined from the fundamental waveform component with the previous expressions. Nevertheless, Steinmetz circuit performance in the presence of waveform distortion is analyzed in (Arendse \& Atkinson-Hope, 2010; Chicco et al., 2009). Several indicators defined in the framework of the symmetrical components are proposed to explain the properties of the Steinmetz circuit under waveform distortion.

The introduction of thyristor-controlled reactive elements due to the recent development of power electronics and the use of step variable capacitor banks allow varying the Steinmetz circuit reactances in order to compensate for the usual single-phase load fluctuations, (Barnes \& Wong, 1991; Chindris et al., 2002). However, the previous design expressions must be considered in current dynamic symmetrization and the power signals are then treated by the controllers in accordance with the Steinmetz procedure for load balancing (ABB Power Transmission, n.d.; Lee \& Wu, 1993; Qingzhu et al., 2010a, 2010b).

\section{Steinmetz circuit impact on power system harmonic response}

The power system harmonic response in the presence of the Steinmetz circuit is analyzed from Fig. 3. Two sources of harmonic disturbances can be present in this system: a three-phase nonlinear load injecting harmonic currents into the system or a harmonic-polluted utility supply system. In the former, the parallel resonance may affect power quality because harmonic voltages due to injected harmonic currents can be magnified. In the latter, series resonance may affect power quality because consumed harmonic currents due to background voltage distortion can also be magnified. Therefore, the system harmonic response depends on the equivalent harmonic impedance or admittance "observed" from the three-phase load or the utility supply system, respectively. This chapter, building on work developed in (Sainz et al., 2007, in press), summarizes the above research on parallel and series resonance location and unifies this study. It provides an expression unique to the location of the parallel and series resonance considering the Steinmetz circuit inductor resistance.

In Fig. 3, the impedances $\underline{Z}_{L k}=R_{L}+j k X_{L}, \underline{Z}_{1 k}=R_{1}+j k X_{1}$ and $\underline{Z}_{2 k}=-j X_{2} / k$ represent the single-phase load, the inductor and the capacitor of the Steinmetz circuit at the fundamental $(k=1)$ and harmonic frequencies $(k>1)$. Note that impedances $\underline{Z}_{L 1}, \underline{Z}_{11}$ and $\underline{Z}_{21}$ correspond to impedances $\underline{Z}_{L}, \underline{Z}_{1}$ and $\underline{Z}_{2}$ in Section 2 , respectively. Moreover, parameter $d_{C}$ is introduced in the study representing the degree of the Steinmetz circuit capacitor degradation from its 
design value [(1) or (3)]. Thus, the capacitor value considered in the harmonic study is $d_{C} \cdot C$, i.e. $-j 1 /\left(d_{C} \cdot C \cdot \omega_{1} \cdot k\right)=-j \cdot\left(X_{2} / k\right) / d_{C}=\underline{Z}_{2 k} / d_{C}$ where $\omega_{1}=2 \pi \cdot f_{1}$ and $f_{1}$ is the fundamental frequency of the supply voltage. This parameter allows examining the impact of the capacitor bank degradation caused by damage in the capacitors or in their fuses on the power system harmonic response. If $d_{C}=1$, the capacitor has the design value [(1) or (3)] whereas if $d_{C}<1$, the capacitor value is lower than the design value.

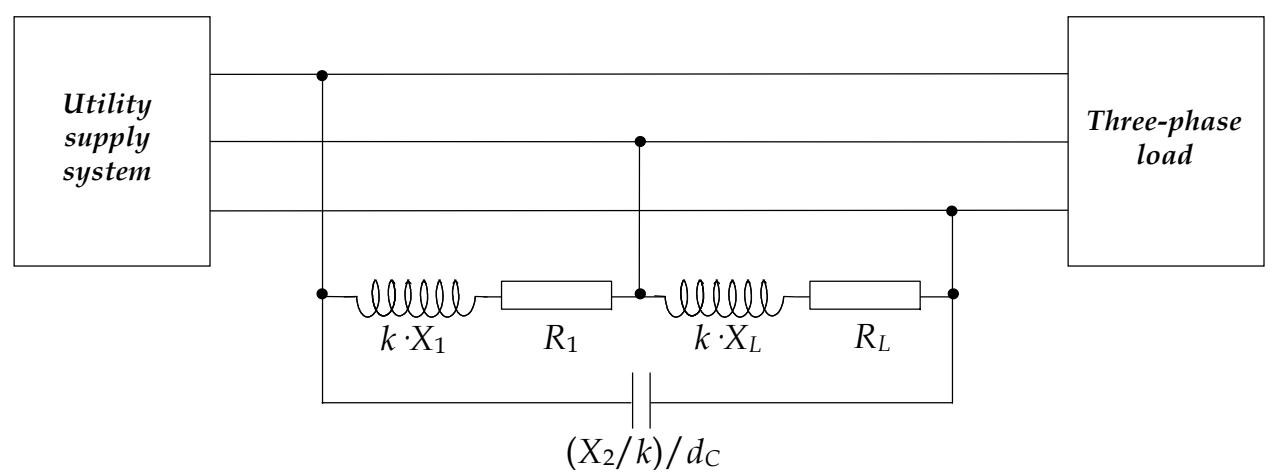

Fig. 3. Power system harmonic analysis in the presence of the Steinmetz circuit.

\subsection{Study of the parallel resonance}

This Section examines the harmonic response of the system "observed" from the three-phase load. It implies analyzing the passive set formed by the utility supply system and the Steinmetz circuit (see Fig. 4). The system harmonic behavior is characterized by the equivalent harmonic impedance matrix, $\underline{Z}_{B u s k}$, which relates the $k^{\text {th }}$ harmonic three-phase voltages and currents at the three-phase load node, $\underline{\mathbf{V}}_{k}=\left[\underline{V}_{A k} \underline{V}_{B k} \underline{V}_{C k}\right]^{\mathrm{T}}$ and $\underline{\mathbf{I}}_{k}=\left[\underline{I}_{A k} \underline{I}_{B k} \underline{I}_{C k}\right]^{\mathrm{T}}$. Thus, considering point $N$ in Fig. 4 as the reference bus, this behavior can be characterized by the voltage node method,

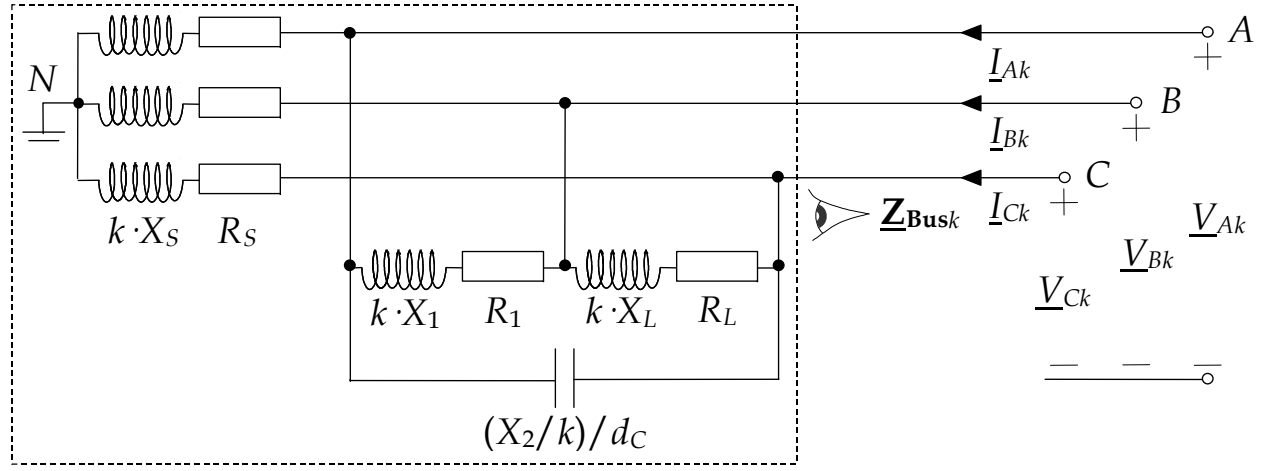

Fig. 4. Study of the parallel resonance in the presence of the Steinmetz circuit. 


$$
\begin{aligned}
\underline{\mathbf{V}}_{k}=\underline{\mathbf{Z}}_{\text {Busk }} \cdot \underline{\mathbf{I}}_{k} & \Rightarrow\left[\begin{array}{l}
\underline{V}_{A k} \\
\underline{V}_{B k} \\
\underline{V}_{C k}
\end{array}\right]=\left[\begin{array}{lll}
\underline{Z}_{A A k} & \underline{Z}_{A B k} & \underline{Z}_{A C k} \\
\underline{Z}_{B A k} & \underline{Z}_{B B k} & \underline{Z}_{B C k} \\
\underline{Z}_{C A k} & \underline{Z}_{C B k} & \underline{Z}_{C C k}
\end{array}\right] \cdot\left[\begin{array}{c}
\underline{I}_{A k} \\
\underline{I}_{B k} \\
\underline{I}_{C k}
\end{array}\right] \\
& =\left[\begin{array}{ccc}
\underline{Y}_{S k}+\underline{Y}_{1 k}+d_{C} \underline{Y}_{2 k} & -\underline{Y}_{1 k} & -d_{C} \underline{Y}_{2 k} \\
-\underline{Y}_{1 k} & \underline{Y}_{S k}+\underline{Y}_{1 k}+\underline{Y}_{L k} & -\underline{Y}_{L k} \\
-d_{C} \underline{Y}_{2 k} & -\underline{Y}_{L k} & \underline{Y}_{S k}+d_{C} \underline{Y}_{2 k}+\underline{Y}_{L k}
\end{array}\right]^{-1}\left[\begin{array}{c}
\underline{I}_{A k} \\
\underline{I}_{B k} \\
\underline{I}_{C k}
\end{array}\right],
\end{aligned}
$$

where

- $\quad \underline{Y}_{S k}=\underline{Z}_{S k^{-1}}=\left(R_{S}+j k X_{S}\right)^{-1}$ corresponds to the admittance of the power supply system, which includes the impedance of the power supply network, the short-circuit impedance of the three-phase transformer and the impedance of the overhead lines feeding the Steinmetz circuit and the three-phase linear load.

- $\quad \underline{Y}_{L k}, \underline{Y}_{1 k}$ and $d_{C} \underline{Y}_{2 k}$ correspond to the admittances of the Steinmetz circuit components (i.e., the inverse of the impedances $\underline{Z}_{L k}, \underline{Z}_{1 k}$ and $\underline{Z}_{2 k} / d_{C}$ in Section 3, respectively).

It can be observed that the diagonal and non-diagonal impedances of the harmonic impedance matrix $\underline{Z}_{B u s k}$ (i.e., $\underline{Z}_{A A k}$ to $\underline{Z}_{C C k}$ ) directly characterize the system harmonic behavior. Diagonal impedances are known as phase driving point impedances (Task force on Harmonic Modeling and Simulation, 1996) since they allow determining the contribution of the harmonic currents injected into any phase $F\left(\underline{I}_{F k}\right)$ to the harmonic voltage of this phase $\left(\underline{V}_{F k}\right)$. Non-diagonal impedances are the equivalent impedances between a phase and the rest of the phases since they allow determining the contribution of the harmonic currents injected into any phase $F\left(\underline{I}_{F k}\right)$ to the harmonic voltage of any other phase $G\left(\underline{V}_{G k}\right.$, with $\left.G \neq F\right)$. Thus, the calculation of both sets of impedances is necessary because a resonance in either of them could cause a high level of distortion in the corresponding voltages and damage harmonic power quality.

As an example, a network as that in Fig. 4 was constructed in the laboratory and its harmonic response (i.e., $\underline{Z}_{\text {Busk }}$ matrix) was measured with the following per unit data $\left(U_{B}=100 \mathrm{~V}\right.$ and $\left.S_{B}=500 \mathrm{VA}\right)$ and considering two cases $\left(d_{C}=1\right.$ and 0.5$)$ :

- Supply system: $\underline{Z}_{S 1}=0.022+j 0.049$ pu.

- $\quad$ Railroad substation: $R_{L}=1.341 \mathrm{pu}, \lambda_{L}=1.0$.

- External balancing equipment: According to (1) and (3), two pairs of reactances were connected with the railroad substation, namely $X_{1 \text {, apr }}=2.323 \mathrm{pu}$ and $X_{2 \text {, apr }}=2.323 \mathrm{pu}$ and $X_{1}=2.234 \mathrm{pu}$ and $X_{2}=2.503 \mathrm{pu}$. The former was calculated by neglecting the inductor resistance (1) and the latter was calculated by considering the actual value of this resistance $(3)\left(R_{1} \approx 0.1342 \mathrm{pu}\right.$, and therefore $\left.\tau_{1} \approx 0.1341 / 2.234=0.06\right)$.

Considering that the system fundamental frequency is $50 \mathrm{~Hz}$, the measurements of the $\underline{Z}_{\text {Busk }}$ impedance magnitudes (i.e., $\left|\underline{Z}_{A A k}\right|$ to $\left|\underline{Z}_{C C k}\right|$ ) with $X_{1 \text {, apr }}$ and $X_{2 \text {, apr }}$ are plotted in Fig. 5 for both cases $\left(d_{C}=1\right.$ in solid lines and $d_{C}=0.5$ in broken lines). It can be noticed that

- The connection of the Steinmetz circuit causes a parallel resonance in the $\underline{Z}_{\text {Busk }}$ impedances that occurs in phases $A$ and $C$, between which the capacitor is connected, and is located nearly at the same harmonic for all the impedances (labeled as $k_{p \text {, meas }}$. This asymmetrical resonant behavior has an asymmetrical effect on the harmonic voltages (i.e., phases $A$ and $C$ have the highest harmonic impedance, and therefore the highest harmonic voltages.) 

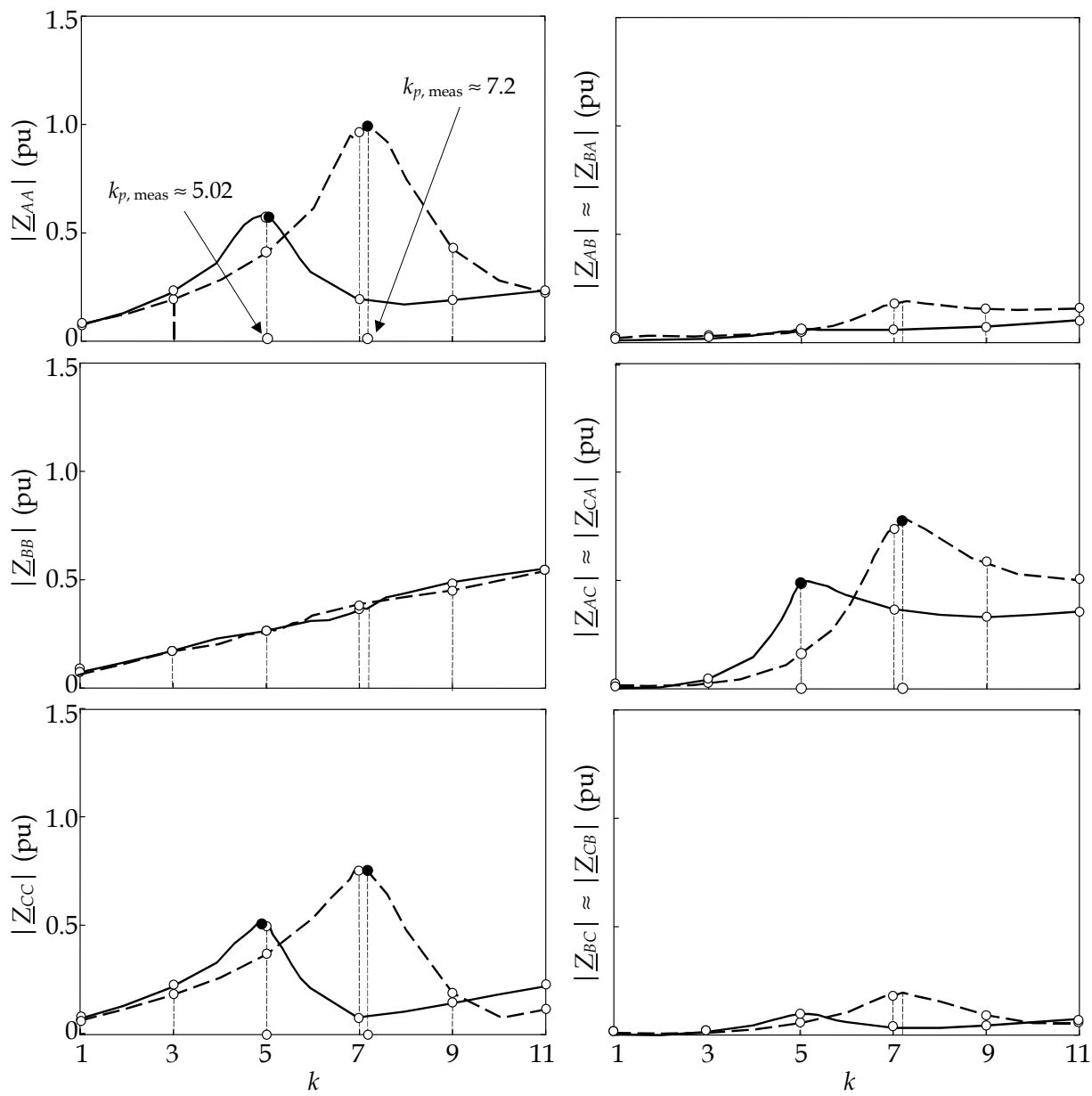

Fig. 5. Measured impedance - frequency matrix in the presence of the Steinmetz circuit with $X_{1, \text { apr }}=X_{2, \text { apr }}=2.323 \mathrm{pu}$ (solid line: $d_{C}=1$; broken line: $d_{C}=0.5$ ).

- In the case of $d_{C}=1$ (in solid lines), the connection of the Steinmetz circuit causes a parallel resonance measured close to the fifth harmonic $\left(k_{p \text {, meas }} \approx 251 / 50=5.02\right.$, where $251 \mathrm{~Hz}$ is the frequency of the measured parallel resonance.)

- If the Steinmetz circuit suffers capacitor bank degradation, the parallel resonance is shifted to higher frequencies. In the example, a $50 \%$ capacitor loss (i.e., $d_{C}=0.5$ in broken lines) shifts the parallel resonance close to the seventh harmonic $\left(k_{s, \text { meas }} \approx 360 / 50=7.2\right.$, where $360 \mathrm{~Hz}$ is the frequency of the measured parallel resonance.)

The measurements of the $\underline{Z}_{\text {Busk }}$ impedance magnitudes (i.e. $\left|\underline{Z}_{A A k}\right|$ to $\left|\underline{Z}_{C C k}\right|$ ) with $X_{1}$ and $X_{2}$ are not plotted for space reasons. In this case, the parallel resonance shifts to $k_{p \text {, meas }} \approx 5.22$ $\left(d_{C}=1\right)$ and $k_{p \text {, meas }} \approx 7.43\left(d_{C}=0.5\right)$ but the general conclusions of the $X_{1}$, apr and $X_{2 \text {, apr }}$ case are true. 


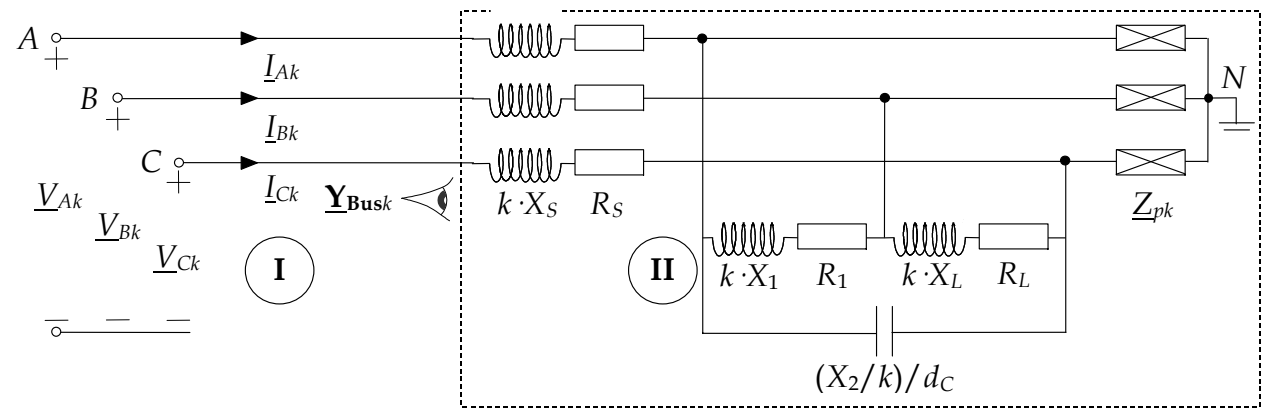

Fig. 6. Study of the series resonance in the presence of the Steinmetz circuit.

\subsection{Study of the series resonance}

This Section studies the harmonic response of the system "observed" from the utility supply system. It implies analyzing the passive set formed by the supply system impedances, the Steinmetz circuit and the three-phase load (see Fig. 6). The system harmonic behavior is characterized by the equivalent harmonic admittance matrix, $\underline{\mathbf{Y}}_{\text {Bus } k}$, which relates the $k^{\text {th }}$ harmonic three-phase currents and voltages at the node I, $\underline{\mathbf{I}}_{k}=\left[\underline{I}_{A k} \underline{I}_{B k} \underline{I}_{C k}\right]^{\mathrm{T}}$ and $\underline{\mathbf{V}}_{k}=\left[\underline{V}_{A k} \underline{V}_{B k} \underline{V}_{C k}\right]^{\mathrm{T}}$, respectively. Thus, considering point $N$ in Fig. 6 as the reference bus, this behavior can be characterized by the voltage node method,

$$
\begin{aligned}
{\left[\begin{array}{c}
\underline{\mathbf{I}}_{k}^{\mathrm{I}} \\
\mathbf{0}
\end{array}\right]=\left[\begin{array}{c|c}
\underline{\mathbf{Y}}_{k}^{\mathrm{I}} & \underline{\mathbf{Y}}_{k}^{\mathrm{I}-\mathrm{II}} \\
\underline{\mathbf{Y}}_{k}^{\mathrm{II}-\mathrm{I}} & \underline{\mathbf{Y}}_{k}^{\mathrm{II}}
\end{array}\right] \cdot\left[\begin{array}{c}
\underline{\mathbf{V}}_{k}^{\mathrm{I}} \\
\underline{\mathbf{V}}_{k}^{\mathrm{II}}
\end{array}\right] } \\
\Rightarrow\left[\begin{array}{c}
\underline{I}_{A k} \\
\underline{I}_{B k} \\
\underline{I}_{C k} \\
\hline 0 \\
0 \\
0
\end{array}\right]=\left[\begin{array}{ccc|ccc}
\underline{Y}_{S k} & 0 & 0 & -\underline{Y}_{S k} & 0 & 0 \\
0 & \underline{Y}_{S k} & 0 & 0 & -\underline{Y}_{S k} & 0 \\
0 & 0 & \underline{Y}_{S k} & 0 & 0 & -\underline{Y}_{S k} \\
\hdashline-\underline{Y}_{S k} & 0 & 0 & \underline{Y}_{T 1 k} & -\underline{Y}_{1 k} & -\underline{d}_{C} \underline{Y}_{2 k} \\
0 & -\underline{Y}_{S k} & 0 & -\underline{Y}_{1 k} & \underline{Y}_{T 2 k} & -\underline{Y}_{L k} \\
0 & 0 & -\underline{Y}_{S k} & -d_{C} \underline{Y}_{2 k} & -\underline{Y}_{L k} & \underline{Y}_{T 3 k}
\end{array}\right] \cdot\left[\begin{array}{l}
\underline{V}_{A k} \\
\underline{V}_{B k} \\
\underline{V}_{C k} \\
\underline{V}_{A k}^{\mathrm{II}} \\
\underline{V}_{B k}^{\mathrm{II}} \\
\underline{V}_{C k}^{\mathrm{II}}
\end{array}\right],
\end{aligned}
$$

and

$$
\underline{\mathbf{I}}_{k}^{\mathrm{I}}=\left[\begin{array}{l}
\underline{I}_{A k} \\
\underline{I}_{B k} \\
\underline{I}_{C k}
\end{array}\right]=\left(\underline{\mathbf{Y}}_{k}^{\mathrm{I}}-\underline{\mathbf{Y}}_{k}^{\mathrm{I}-\mathrm{II}} \underline{\mathbf{Y}}_{k}^{\mathrm{II}} \underline{\mathbf{Y}}_{k}^{\mathrm{II}-\mathrm{I}}\right) \underline{\mathbf{V}}_{k}^{\mathrm{I}}=\underline{\mathbf{Y}}_{\mathrm{Busk}} \underline{\mathbf{V}}_{k}^{\mathrm{I}}=\left[\begin{array}{lll}
\underline{Y}_{A A k} & \underline{Y}_{A B k} & \underline{Y}_{A C k} \\
\underline{Y}_{B A k} & \underline{\underline{Y}}_{B B k} & \underline{\underline{Y}}_{B C k} \\
\underline{Y}_{C A k} & \underline{Y}_{C B k} & \underline{Y}_{C C k}
\end{array}\right] \cdot\left[\begin{array}{l}
\underline{V}_{A k} \\
\underline{V}_{B k} \\
\underline{V}_{C k}
\end{array}\right],
$$

where

$$
\begin{aligned}
& \underline{Y}_{T 1 k}=\underline{Y}_{S k}+\underline{Y}_{P k}+\underline{Y}_{1 k}+d_{C} \underline{Y}_{2 k} \quad ; \quad \underline{Y}_{T 2 k}=\underline{Y}_{S k}+\underline{Y}_{P k}+\underline{Y}_{1 k}+\underline{Y}_{L k} \\
& \underline{Y}_{T 3 k}=\underline{Y}_{S k}+\underline{Y}_{P k}+\underline{Y}_{L k}+d_{C} \underline{Y}_{2 k} .
\end{aligned}
$$

Admittances $\underline{Y}_{S k}, \underline{Y}_{L k}, \underline{Y}_{1 k}$ and $d_{C} \underline{Y}_{2 k}$ were already introduced in the parallel resonance location and $\underline{Y}_{P k}=\underline{Z}_{P k^{-1}}=g_{\mathrm{LM} \#}\left(\left|\underline{Z}_{P 1}\right|, \lambda_{P}, k\right)$ is the three-phase load admittance. The function $g_{\mathrm{LM} \#}(\cdot)$ represents the admittance expressions of the load models 1 to 7 proposed in (Task 
force on Harmonic Modeling and Simulation, 2003), and $\left|\underline{Z}_{P 1}\right|$ and $\lambda_{P}$ are the magnitude and the displacement power factor of the load impedances at the fundamental frequency, respectively. For example, the expression $g_{\mathrm{LM} 1}\left(\left|\underline{Z}_{P 1}\right|, \lambda_{P}, k\right)=1 /\left\{\left|\underline{Z}_{P 1}\right| \cdot\left(\lambda_{P}+j k\left(1-\lambda_{P}^{2}\right)^{1 / 2}\right)\right\}$ corresponds to the series R-L impedance model, i.e. the model LM1 in (Task force on Harmonic Modeling and Simulation, 2003).

It can be observed that the diagonal and non-diagonal admittances of the harmonic admittance matrix $\underline{Y}_{\text {Busk }}$ (i.e., $\underline{Y}_{A A k}$ to $\underline{Y}_{C C k}$ ) directly characterize system harmonic behavior. Diagonal admittances allow determining the contribution of the harmonic voltages at any phase $F\left(\underline{V}_{F k}\right)$ to the harmonic currents consumed at this phase $\left(\underline{I}_{F k}\right)$. Non-diagonal admittances allow determining the contribution of the harmonic voltages at any phase $F$ $\left(\underline{V}_{F k}\right)$ to the harmonic currents consumed at any other phase $G\left(\underline{I}_{G k}\right.$, with $\left.G \neq F\right)$. Thus, the calculation of both sets of admittances is necessary because this resonance could lead to a high value of the admittance magnitude, magnify the harmonic currents consumed in the presence of background voltage distortion and damage harmonic power quality.

As an example, a network as that in Fig. 6 was constructed in the laboratory and its harmonic response (i.e., $\underline{\mathbf{Y}}_{\text {Busk }}$ matrix) was measured with the following per unit data $\left(U_{B}=100 \mathrm{~V}\right.$ and $\left.S_{B}=500 \mathrm{VA}\right)$ and considering two cases $\left(d_{C}=1\right.$ and 0.5$)$ :

- $\quad$ Supply system: $\underline{Z}_{S 1}=0.076+j 0.154 \mathrm{pu}$.

- $\quad$ Railroad substation: $R_{L}=1.464 \mathrm{pu}, \lambda_{L}=0.95$.

- External balancing equipment: According to (1) and (3), two pairs of reactances were connected with the railroad substation, namely $X_{1 \text {, apr }}=1.790 \mathrm{pu}$ and $X_{2 \text {, apr }}=6.523 \mathrm{pu}$ and $X_{1}=1.698 \mathrm{pu}$ and $X_{2}=10.03 \mathrm{pu}$. The former was calculated by neglecting the inductor resistance (1) and the latter was calculated by considering the actual value of this resistance $(3)\left(R_{1} \approx 0.1342 \mathrm{pu}\right.$, and therefore $\left.\tau_{1} \approx 0.1341 / 1.698=0.079\right)$.

- $\quad$ Three-phase load: Grounded wye series R-L impedances with $\left|\underline{Z}_{P_{1}}\right|=30.788 \mathrm{pu}$ and $\lambda_{P}=0.95$ are connected, i.e. the three-phase load model LM1 in (Task force on Harmonic Modeling and Simulation, 2003).

Considering that the system fundamental frequency is $50 \mathrm{~Hz}$, the measurements of the $\underline{\mathbf{Y}}_{\mathrm{Busk}}$ admittance magnitudes (i.e. $\left|\underline{Y}_{A A k}\right|$ to $\left|\underline{Y}_{C C k}\right|$ ) with $X_{1 \text {, apr }}$ and $X_{2 \text {, apr }}$ are plotted in Fig. 7 for both cases $\left(d_{C}=1\right.$ in solid lines and $d_{C}=0.5$ in broken lines). It can be noted that

- The connection of the Steinmetz circuit causes a series resonance in the $\underline{\mathbf{Y}}_{\text {Busk }}$ admittances that occurs in phases $A$ and $C$, between which the capacitor is connected, and is located nearly at the same harmonic for all the admittances (labeled as $\left.k_{s, \text { meas }}\right)$. This asymmetrical resonant behavior has an asymmetrical effect on the harmonic consumed currents (i.e., phases $A$ and $C$ have the highest harmonic admittance, and therefore the highest harmonic consumed currents.)

- In the case of $d_{C}=1$ (in solid lines), the connection of the Steinmetz circuit causes a series resonance measured close to the fifth harmonic $\left(k_{s, \text { meas }} \approx 255 / 50=5.1\right.$, where $255 \mathrm{~Hz}$ is the frequency of the measured series resonance.)

- If the Steinmetz circuit suffers capacitor bank degradation, the series resonance is shifted to higher frequencies. In the example, a $50 \%$ capacitor loss (i.e., $d_{C}=0.5$ in broken lines) shifts the series resonance close to the seventh harmonic $\left(k_{s, \text { meas }} \approx 365 / 50=7.3\right.$, where $365 \mathrm{~Hz}$ is the frequency of the measured series resonance.) The measurements of the $\underline{Y}_{\text {Busk }}$ admittance magnitudes (i.e., $\left|\underline{Y}_{A A k}\right|$ to $\left|\underline{Y}_{C C k}\right|$ ) with $X_{1}$ and $X_{2}$ are not plotted for space reasons. In this case, the series resonance shifts to $k_{s, \text { meas }} \approx 6.31\left(d_{C}=1\right)$ and $k_{s, \text { meas }} \approx 8.83\left(d_{C}=0.5\right)$ but the general conclusions of the $X_{1 \text {, apr }}$ and $X_{2 \text {, apr }}$ case are true. 

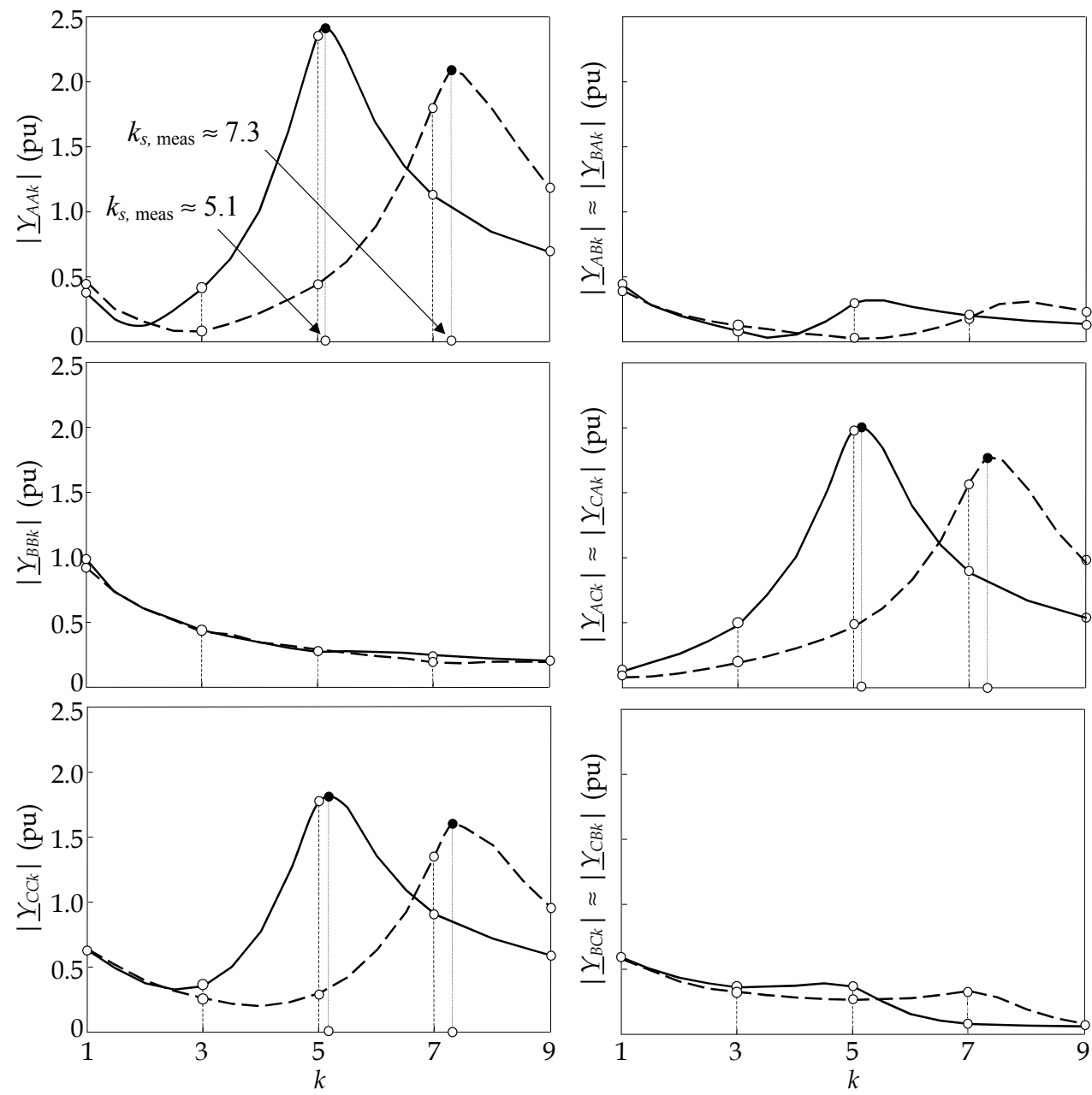

Fig. 7. Measured admittance - frequency matrix in the presence of the Steinmetz circuit with $X_{1, \text { apr }}=1.790 \mathrm{pu}$ and $X_{2, \text { apr }}=6.523 \mathrm{pu}$ (solid line: $d_{C}=1$; broken line: $d_{C}=0.5$ ).

\section{Analytical study of power system harmonic response}

In this Section, the magnitudes of the most critical $\underline{Z}_{\text {Busk }}$ impedances (i.e., $\left|\underline{Z}_{A A k}\right|,\left|\underline{Z}_{C C k}\right|$, $\left|\underline{Z}_{A C k}\right|$ and $\left.\left|\underline{Z}_{C A k}\right|\right)$ and $\underline{Y}_{\text {Busk }}$ admittances (i.e., $\left|\underline{Y}_{A A k}\right|,\left|\underline{Y}_{C C k}\right|,\left|\underline{Y}_{A C k}\right|$ and $\left|\underline{Y}_{C A k}\right|$ ) are analytically studied in order to locate the parallel and series resonance, respectively.

\subsection{Power system harmonic characterization}

The most critical $\underline{\mathbf{Z}}_{\text {Busk }}$ impedances are obtained from (5): 


$$
\begin{aligned}
& \left|\underline{Z}_{A A k}\right|=\left|\frac{\underline{Y}_{S k}^{2}+\underline{Y}_{S k}\left(\underline{Y}_{S t z 1 k}+\underline{Y}_{L k}\right)+\underline{Y}_{S t z 2 k}}{\underline{Y}_{S k} \underline{D}_{k}}\right| ;\left|\underline{Z}_{C C k}\right|=\left|\frac{\underline{Y}_{S k}^{2}+\underline{Y}_{S k}\left(\underline{Y}_{S t z 1 k}+\underline{Y}_{1 k}\right)+\underline{Y}_{S t z 2 k}}{\underline{Y}_{S k} \underline{D}_{k}}\right| \\
& \left|\underline{Z}_{A C k}\right|=\left|\underline{Z}_{C A k}\right|=\left|\frac{\underline{Y}_{S t z 2 k}+d_{C} \underline{Y}_{2 k} \underline{Y}_{S k}}{\underline{Y}_{S k} \underline{D}_{k}}\right| \text {, }
\end{aligned}
$$

where

$$
\begin{aligned}
& \underline{Y}_{S t z 1 k}=\underline{Y}_{1 k}+d_{C} \underline{Y}_{2 k}+\underline{Y}_{L k} \quad ; \quad \underline{Y}_{S t z 2 k}=\underline{Y}_{L k} \underline{Y}_{1 k}+\underline{Y}_{L k} d_{C} \underline{Y}_{2 k}+\underline{Y}_{1 k} d_{C} \underline{Y}_{2 k} \\
& \underline{D}_{k}=\underline{Y}_{S k}^{2}+2 \underline{Y}_{S k} \underline{Y}_{S t z 1 k}+3 \cdot \underline{Y}_{S t z 2 k} .
\end{aligned}
$$

The harmonic of the parallel resonance numerically obtained as the maximum value of the above impedance magnitudes is located nearly at the same harmonic for all the impedances (Sainz et al., 2007) and labeled as $k_{p, \mathrm{n}}$.

The most critical $\underline{\mathbf{Y}}_{\text {Busk }}$ admittances are obtained from (7):

$$
\begin{aligned}
& \left|\underline{Y}_{A A k}\right|=\left|\frac{\underline{Y}_{S k}\left(\underline{Y}_{S k} \underline{N}_{A A k}+\underline{Y}_{P k} \underline{N}_{A A k}^{(P)}\right)}{\underline{Y}_{S k} \underline{D}_{k}+\underline{Y}_{P k} \cdot \underline{D}_{k}^{(P)}}\right| ; \quad\left|\underline{Y}_{C C k}\right|=\mid \frac{\underline{Y}_{S k}\left(\underline{Y}_{S k} \underline{N}_{C C k}+\underline{Y}_{P k} \frac{\left.N_{C C k}^{(P)}\right)}{\underline{Y}_{S k} \underline{D}_{k}+\underline{Y}_{P k} \cdot \underline{D}_{k}^{(P)}} \mid\right.}{\left|\underline{Y}_{A C k}\right|=\left|\underline{Y}_{C A k}\right|=\left|\frac{\underline{Y}_{S k}^{2}\left(\underline{Y}_{S k} d_{C} \underline{Y}_{2 k}+\underline{Y}_{S t z 2 k}+\underline{Y}_{P k} d_{C} \underline{Y}_{2 k}\right)}{\underline{Y}_{S k} \underline{D}_{k}+\underline{Y}_{P k} \cdot \underline{D}_{k}^{(P)}}\right|,}
\end{aligned}
$$

where

$$
\begin{aligned}
& \underline{N}_{A A k}=\underline{Y}_{S k}\left(\underline{Y}_{1 k}+d_{C} \underline{Y}_{2 k}\right)+2 \cdot \underline{Y}_{S t z 2 k} \quad ; \quad \underline{N}_{C C k}=\underline{Y}_{S k}\left(\underline{Y}_{L k}+d_{C} \underline{Y}_{2 k}\right)+2 \cdot \underline{Y}_{S t z 2 k} \\
& \underline{N}_{A A k}^{(P)}=\underline{Y}_{P k}^{2}+2 \cdot\left(\underline{Y}_{S k}+\underline{Y}_{S t z 1 k}\right) \underline{Y}_{P k}+3 \cdot\left(\underline{Y}_{S t z 2 k}+\underline{Y}_{S k}\left(\underline{Y}_{1 k}+d_{C} \underline{Y}_{2 k}\right)\right)+\underline{Y}_{S k}\left(\underline{Y}_{S k}+2 \cdot \underline{Y}_{L k}\right) \\
& \underline{N}_{C C k}^{(P)}=\underline{Y}_{P k}^{2}+2 \cdot\left(\underline{Y}_{S k}+\underline{Y}_{S t z 1 k}\right) \underline{Y}_{P k}+3 \cdot\left(\underline{Y}_{S t z 2 k}+\underline{Y}_{S k}\left(\underline{Y}_{L k}+d_{C} \underline{Y}_{2 k}\right)\right)+\underline{Y}_{S k}\left(\underline{Y}_{S k}+2 \cdot \underline{Y}_{1 k}\right) \\
& \underline{D}_{k}^{(P)}=\underline{Y}_{P k}^{2}+\left(3 \underline{Y}_{S k}+2 \cdot \underline{Y}_{S t z 1 k}\right) \underline{Y}_{P k}+3 \cdot\left(\underline{Y}_{S k}^{2}+\underline{Y}_{S t z 2 k}\right)+4 \underline{Y}_{S k} \underline{Y}_{S t z 1 k} .
\end{aligned}
$$

The harmonic of the series resonance numerically obtained as the maximum value of the above admittance magnitudes is located nearly at the same harmonic for all the admittances (Sainz et al., in press) and labeled as $k_{s, n}$.

Since the expressions of the $\underline{\mathbf{Y}}_{\text {Busk }}$ admittances (11) are too complicated to be analytically analyzed, the admittance $\underline{Y}_{P k}$ is not considered in their determination (i.e., $\underline{Y}_{P k}=0$ ), and they are approximated to

$$
\begin{aligned}
& \left|\underline{Y}_{A A k}\right| \approx\left|\underline{Y}_{A A k, \text { apx }}\right|=\left|\frac{\underline{Y}_{S k} \underline{N}_{A A k}}{\underline{D}_{k}}\right| ;\left|\underline{Y}_{C C k}\right| \approx\left|\underline{Y}_{C C k, \text { apx }}\right|=\left|\frac{\underline{Y}_{S k} \underline{N}_{C C K}}{\underline{D}_{k}}\right| \\
& \left|\underline{Y}_{A C k}\right|=\left|\underline{Y}_{C A k}\right| \approx\left|\underline{Y}_{A C k, \text { apx }}\right|=\left|\underline{Y}_{A C k, \text { apx }}\right|=\left|\frac{\underline{Y}_{S k}\left(\underline{Y}_{S k} d_{C} \underline{Y}_{2 k}+\underline{Y}_{S t z 2 k}\right)}{\underline{D}_{k}}\right| .
\end{aligned}
$$

This approximation is based on the fact that, the three-phase load does not influence the series resonance significantly if large enough, (Sainz et al., 2009b). The harmonic of the series resonance numerically obtained as the maximum value of the above admittance magnitudes is located nearly at the same harmonic for all the admittances (Sainz et al., in press) and labeled as $k_{s, \text { napx. }}$ 
It must be noted that (9) and (13) depend on the supply system and the Steinmetz circuit admittances (i.e., $\underline{Y}_{S k}, \underline{Y}_{L k}, \underline{Y}_{1 k}$ and $d_{C} \cdot \underline{Y}_{2 k}$ ) and (11) depends on the previous admittances and three-phase load admittances (i.e., $\underline{Y}_{S k}, \underline{Y}_{L k}, \underline{Y}_{1 k}, d_{C} \underline{Y}_{2 k}$ and $\left.\underline{Y}_{P k}\right)$. In the study, these admittances are written as

$$
\begin{aligned}
& \underline{Y}_{S k} \approx-j \frac{1}{k X_{S}} ; \underline{Y}_{L k}=\frac{1}{R_{L}\left(1+j k \tau_{L}\right)} ; \underline{Y}_{1 k} \approx \frac{1}{j k \cdot X_{1}}=-j \frac{1}{k}\left(\frac{\lambda_{L} \tau_{1}}{\lambda_{1}}\right)^{2} \frac{1+\sqrt{3} \tau_{L}}{R_{L}\left(\sqrt{3}-\tau_{1}\right)} \\
& d_{C} \underline{Y}_{2 k}=\frac{d_{C}}{-j X_{2} / k}=j k \frac{d_{C} \lambda_{L}^{2}\left\{\left(1-\sqrt{3} \tau_{L}\right)-\tau_{1}\left(\sqrt{3}+\tau_{L}\right)\right\}}{R_{L}\left(\sqrt{3}-\tau_{1}\right)} ; \underline{Y}_{P k}=g_{\text {LM }}\left(\left|\underline{Z}_{P 1}\right|, \lambda_{P}, k\right),
\end{aligned}
$$

where (3) is used to obtain the Steinmetz circuit components $X_{1}$ and $X_{2}$, and $g_{\mathrm{LM} \#}(\cdot)$ represents the three-phase load admittance models 1 to 7 proposed in (Task force on Harmonic Modeling and Simulation, 2003). Thus, it is observed that the $\underline{\mathbf{Z}}_{\text {Busk }}$ impedances and $\underline{\mathbf{Y}}_{\text {Busk }}$ admittances are functions of eight variables, namely

- the harmonic order $k$,

- the supply system fundamental reactance $X_{S}$,

- the single-phase load resistance $R_{L}$

- $\quad$ the parameter $\tau_{L}$, i.e. the single-phase load fundamental displacement power factor $\lambda_{L}$ (2),

- the R/X ratio of the Steinmetz circuit inductor $\tau_{1}$,

- the degradation parameter $d_{C}$,

- the magnitude of the linear load fundamental impedance $\left|\underline{Z}_{P 1}\right|$ and

- the linear load fundamental displacement power factor $\lambda_{P}$.

It is worth pointing out that the resistance of the supply system is neglected (i.e., $\left.\underline{Z}_{S k}=R_{S}+j k X_{S} \approx j k X_{S}\right)$ and the resistance of the Steinmetz circuit is only considered in the inductor design [i.e., $\underline{Z}_{1 k}=R_{1}+j k X_{1} \approx j k X_{1}$ and $\underline{Z}_{2 k}=-j \cdot X_{2} / k$, with $X_{1}$ and $X_{2}$ obtained from (3)]. This is because the real part of these impedances does not modify the series resonance frequency significantly (Sainz et al., 2007, 2009a) while the impact of $R_{1}$ on Steinmetz circuit design modifies the resonance. This influence is not considered in the previous harmonic response studies.

In order to reduce the above number of variables, the $\underline{\mathbf{Z}}_{\text {Busk }}$ impedances and $\underline{\mathbf{Y}}_{\text {Busk }}$ admittances are normalized with respect to the supply system fundamental reactance $X_{S}$. For example, the normalized magnitudes $\left|\underline{Z}_{A A k}\right|_{\mathrm{N}}$ and $\left|\underline{Y}_{A A k}\right|_{\mathrm{N}}$ can be expressed from (9) and (11) as

$$
\begin{aligned}
& \left|\underline{Z}_{A A k}\right|_{N}=\frac{\left|\underline{Z}_{A A k}\right|}{X_{S}}=\frac{1}{X_{S}}\left|\frac{X_{S}^{2}\left\{\underline{Y}_{S k}^{2}+\underline{Y}_{S k}\left(\underline{Y}_{S t z 1 k}+\underline{Y}_{L k}\right)+\underline{Y}_{S t z 2 k}\right\}}{X_{S}^{2} \underline{Y}_{S k} \underline{D}_{k}}\right|, \\
& \left|\underline{Y}_{A A k}\right|_{\mathrm{N}}=X_{S}\left|\underline{Y}_{A A k}\right|_{\mathrm{N}}=X_{S}\left|\frac{X_{S}^{3} \underline{Y}_{S k}\left(\underline{Y}_{S k} \underline{N}_{A A k}+\underline{Y}_{P k} \underline{N}_{A A k}^{(P)}\right)}{X_{S}^{3}\left\{\underline{Y}_{S k} \underline{D}_{k}+\underline{Y}_{P k} \cdot \underline{D}_{k}^{(P)}\right\}}\right|,
\end{aligned}
$$

where (15) has only terms $X_{S} \cdot \underline{Y}_{S k}, X_{S} \cdot \underline{Y}_{L k}, X_{S} \cdot \underline{Y}_{1 k}, X_{S} \cdot d_{C} \cdot \underline{Y}_{2 k}$ and $X_{S} \cdot \underline{Y}_{P k}$, which can be rewritten from (14) as 


$$
\begin{aligned}
& X_{S} \underline{Y}_{S k}=-j \frac{1}{k}, \quad X_{S} \underline{Y}_{L k}=\frac{1}{r_{L}\left(1+j k \tau_{L}\right)}, \quad X_{S} \underline{Y}_{P k}=g_{\mathrm{LM} \#, \mathrm{~N}}\left(z_{P}, \lambda_{p}, k\right) \\
& X_{S} \underline{Y}_{1 k}=\frac{X_{S}}{j k \cdot X_{1}}=-j \frac{1}{k \cdot x_{1}}=-j \frac{1}{k}\left(\frac{\lambda_{L} \tau_{1}}{\lambda_{1}}\right)^{2} \frac{1+\sqrt{3} \tau_{L}}{r_{L}\left(\sqrt{3}-\tau_{1}\right)}, \\
& X_{S} d_{C} \underline{Y}_{2 k}=\frac{X_{S} d_{C}}{-j X_{2} / k}=j k \frac{d_{C}}{x_{2}}=j k \frac{d_{C} \lambda_{L}^{2}\left\{\left(1-\sqrt{3} \tau_{L}\right)-\tau_{1}\left(\sqrt{3}+\tau_{L}\right)\right\}}{r_{L}\left(\sqrt{3}-\tau_{1}\right)},
\end{aligned}
$$

where $g_{\mathrm{LM} \#, \mathrm{~N}}(\cdot)$ represents the normalized expressions of the three-phase load models 1 to 7 proposed in (Task force on Harmonic Modeling and Simulation, 2003), $r_{L}=R_{L} / X_{S}$ and $z_{P}=\left|\underline{Z}_{P 1}\right| / X_{S}$. The normalized expressions $g_{\mathrm{LM}, \mathrm{N}}(\cdot)$ are obtained and presented in (Sainz et al., 2009a) but are not included in the present text for space reasons. As an example, the normalized expression of model LM1 in (Task force on Harmonic Modeling and Simulation, $2003)$ is $g_{\mathrm{LM} 1, \mathrm{~N}}\left(\mathrm{z}_{p}, \lambda_{P}, k\right)=1 /\left\{\mathrm{z}_{p} \cdot\left(\lambda_{P}+j k\left(1-\lambda_{P}{ }^{2}\right)^{1 / 2}\right)\right\}$ (Sainz et al., 2009a).

From (15), it is interesting to note that the normalization does not modify the parallel and series resonance $\left(k_{p, \mathrm{n}}, k_{s, \mathrm{n}}\right.$ and $\left.k_{s, \mathrm{napx}}\right)$, but the number of variables of the normalized $\underline{\mathbf{Z}}_{\mathrm{Busk}}$ impedances and $\underline{\mathbf{Y}}_{\text {Busk }}$ admittances are reduced to seven (16), i.e.,

- the harmonic order $k$,

- the ratio of the single-phase load resistance to the supply system fundamental reactance $r_{L}=R_{L} / X_{S}$

- $\quad$ the parameter $\tau_{L}$, i.e. the single-phase load fundamental displacement power factor $\lambda_{L}$ (2),

- $\quad$ the $\mathrm{R} / \mathrm{X}$ ratio of the Steinmetz circuit inductor $\tau_{1}$,

- the degradation parameter $d_{C}$,

- the ratio of the linear load fundamental impedance magnitude to the supply system fundamental reactance $z_{P}=\left|\underline{Z}_{P 1}\right| / X_{S}$ and

- the linear load fundamental displacement power factor $\lambda_{P}$.

Moreover, the usual ranges of values of these variables can be obtained by relating them with known parameters to study resonances under power system operating conditions. Thus, the power system harmonic response is analyzed for the following variable ranges:

- Harmonic: $k=(1, \ldots, 15)$.

- $\quad$ Single-phase load: $r_{L}=(5, \ldots, 1000)$ and $\lambda_{L}=(0.9, \ldots, 1)$.

- Steinmetz circuit inductor: $\tau_{1}=(0, \ldots, 0.5)$.

- Degradation parameter: $d_{C}=(0.25, \ldots, 1)$.

- $\quad$ Linear load: $\mathrm{z}_{P}=(5, \ldots, 1000)$ and $\lambda_{P}=(0.9, \ldots, 1)$.

The ratios $r_{L}$ and $z_{P}$ are equal to the ratios $\lambda_{L} \cdot S_{S} / S_{L}$ and $S_{S} / S_{P}$ (Sainz et al., 2009a), where $S_{S}$ is the short-circuit power at the PCC bus, $S_{L}$ is the apparent power of the single-phase load and $S_{P}$ is the apparent power of the three-phase load. Thus, the range of these ratios is determined considering the usual values of the ratios $S_{S} / S_{L}$ and $S_{S} / S_{P}$ (Chen, 1994; Chen \& Kuo, 1995) and the fundamental displacement power factors $\lambda_{L}$ and $\lambda_{P}$.

In next Section, the normalized magnitudes of the most critical $\underline{Z}_{\text {Busk }}$ impedances (9) and approximated $\underline{\mathbf{Y}}_{\text {Busk }}$ admittances (13) are analytically studied to obtain simple expressions for locating the parallel and series resonance. Thus, these expressions are functions of the following five variables only: $k, r_{L}=R_{L} / X_{S}, \lambda_{L}, \tau_{1}$ and $d_{C}$. 
The series resonance study in the next Section is only valid for $z_{P}>20$ because the approximation of not considering the three-phase load admittance (i.e., $\underline{Y}_{P k}=0$ ) is based on the fact that this load does not strongly influence the series resonance if $z_{P}$ is above 20 . Nevertheless, the magnitude of the normalized admittances at the resonance point is low for $\mathrm{Z}_{P}<20$ and the consumed currents do not increase significantly (Sainz et al., 2009a).

\subsection{Analytical location of the parallel and series resonance}

It is numerically verified that the parallel and series resonance, i.e. the maximum magnitude values of the normalized $\underline{\mathbf{Z}}_{\text {Busk }}$ impedances and approximated $\underline{\mathbf{Y}}_{\text {Busk }}$ admittances [obtained from (9) and (13)] with respect to the harmonic $k$ respectively, coincide with the minimum value of their denominators for the whole range of system variables. Thus, from (9) and (13), these denominators can be written as

$$
\begin{aligned}
& \operatorname{Den}\left(\left|\underline{Y}_{A A k, \text { apx }}\right|_{N}\right)=\operatorname{Den}\left(\left|\underline{Y}_{C C k, \text { apx }}\right|_{N}\right)=k \cdot \operatorname{Den}\left(\left|\underline{Y}_{A C k, \text { apx }}\right|_{N}\right) \\
& =k \cdot \operatorname{Den}\left(\left|\underline{Z}_{A A k}\right|_{N}\right)=k \cdot \operatorname{Den}\left(\left|\underline{Z}_{C C k}\right|_{N}\right)=k \cdot \operatorname{Den}\left(\left|\underline{Z}_{A C k}\right|_{N}\right) \\
& =k\left|k\left(H_{1} k^{2}+H_{2}\right)+j \cdot\left(H_{3} k^{2}+H_{4}\right)\right|,
\end{aligned}
$$

where

$$
\begin{aligned}
& H_{1}=r_{L} \tau_{L}\left(2 x_{1}+3\right)+3 x_{1} \quad ; \quad H_{2}=-\left(\frac{x_{2}}{d_{C}}\right)\left(x_{1}\left(r_{L} \tau_{L}+2\right)+2 r_{L} \tau_{L}+3\right) \\
& H_{3}=r_{L}\left(2 x_{1}+3\right) ; H_{4}=-\left(\frac{x_{2}}{d_{C}}\right) r_{L}\left(x_{1}+2\right)
\end{aligned}
$$

and

$$
x_{1}=\left(\frac{\lambda_{1}}{\lambda_{L} \tau_{1}}\right)^{2} \frac{r_{L}\left(\sqrt{3}-\tau_{1}\right)}{1+\sqrt{3} \tau_{L}} \quad ; \quad x_{2}=\frac{r_{L}\left(\sqrt{3}-\tau_{1}\right)}{\lambda_{L}^{2}\left\{\left(1-\sqrt{3} \tau_{L}\right)-\tau_{1}\left(\sqrt{3}+\tau_{L}\right)\right\}} .
$$

From (17), it is observed that the series resonances of $\left|\underline{Y}_{A A k \text {, apx }}\right|_{\mathrm{N}}$ and $\left|\underline{Y}_{C C k \text {, apx }}\right|_{\mathrm{N}}$ admittances match up because their denominators are the same. This is true for the series resonance of $\left|\underline{Y}_{A C k, \text { apx }}\right|_{\mathrm{N}}$ admittance and the parallel resonance of $\left|\underline{Z}_{A A k}\right|_{\mathrm{N}},\left|\underline{Z}_{C C k}\right|_{\mathrm{N}}$ and $\left|\underline{Z}_{A C k}\right|_{N}$ impedances. However, despite the discrepancy in the denominator degrees, it is numerically verified that the harmonic of the parallel and series resonance is roughly the same for all the impedances and admittances. Then, these resonances are located from the minimum value of the $\left|\underline{Y}_{A C k \text {, apx }}\right|_{\mathrm{N}},\left|\underline{Z}_{A A k}\right|_{\mathrm{N}},\left|\underline{Z}_{C C k}\right|_{\mathrm{N}}$ and $\left|\underline{Z}_{A C k}\right|_{\mathrm{N}}$ denominator because it is the simplest. In the study, this denominator is labeled as $\left|\underline{\Delta}_{k}\right|$ for clarity and the harmonic of the parallel and series resonance numerically obtained as the minimum value of $\left|\underline{\Delta}_{k}\right|$ is labeled as $k_{r, \Delta}$ for both resonances. This value is analytically located by equating to zero the derivative of $\left|\underline{\Delta}_{k}\right|^{2}$ with respect to $k$, which can be arranged in the following form:

$$
\frac{\partial\left(\left|\underline{\Delta}_{k}\right|^{2}\right)}{\partial k}=6 H_{1} k\left(k^{4}+G_{1} k^{2}+G_{2}\right) \quad \Rightarrow \quad k_{r, \mathrm{a}}^{4}+G_{1} k_{r, \mathrm{a}}^{2}+G_{2}=0,
$$


where $k_{r, \text { a }}$ is the harmonic of the parallel and series resonance analytically obtained and

$$
G_{1}=\frac{2 \cdot\left(2 H_{2} H_{1}+H_{3}^{2}\right)}{3 \cdot H_{1}^{2}} \quad ; \quad G_{2}=\frac{H_{2}^{2}+2 \cdot H_{4} H_{3}}{3 \cdot H_{1}^{2}}
$$

Thus, the root of equation (20) allows locating the parallel and series resonance:

$$
k_{r, \mathrm{a}}=\sqrt{\frac{-G_{1}+\sqrt{G_{1}^{2}-4 \cdot G_{2}}}{2}} .
$$

(a)
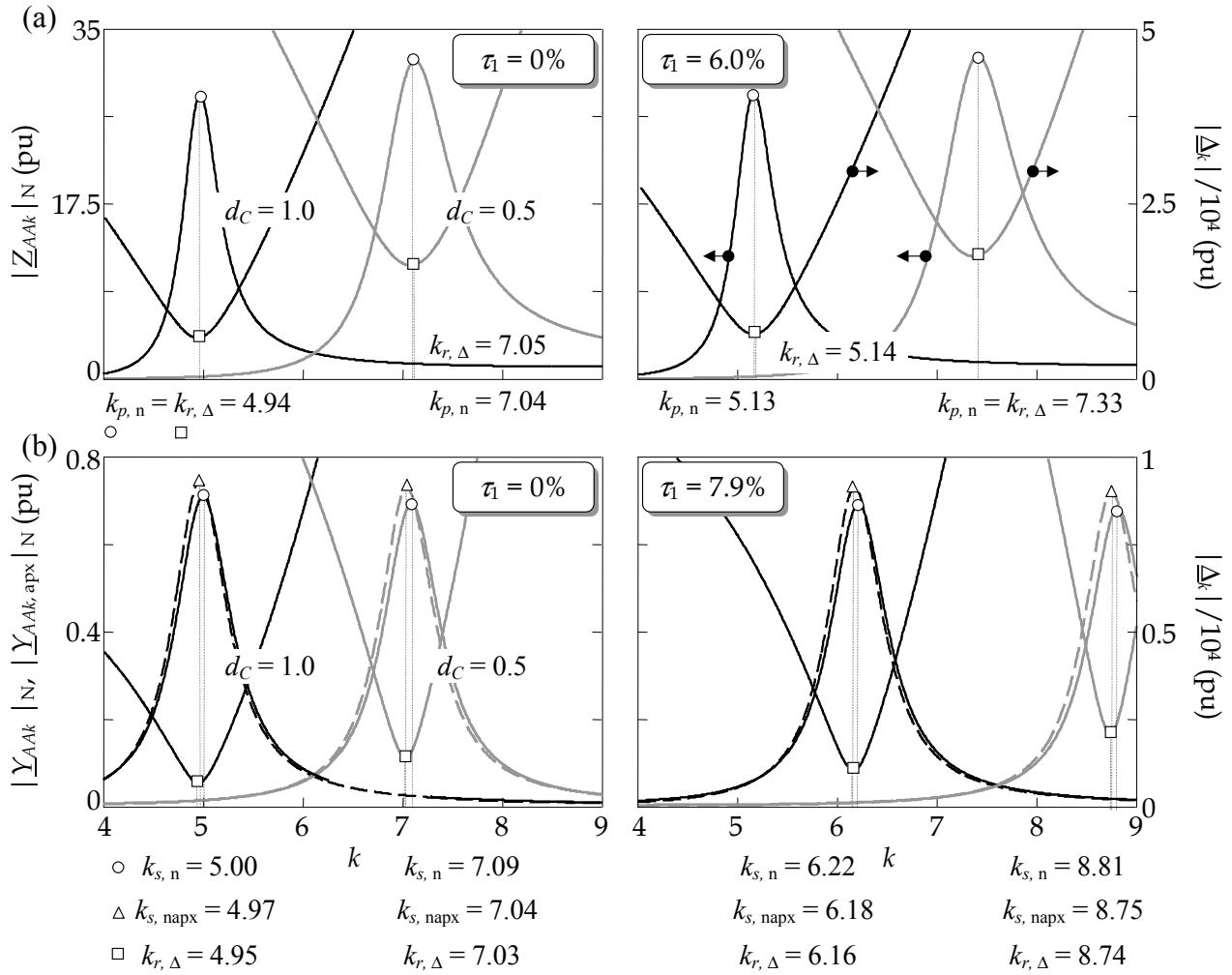

Fig. 8. Resonance location: a) Parallel resonance (power system data in Section 3.1: $X_{S}=0.049 \mathrm{pu}, R_{L}=1.341 \mathrm{pu}$ and $\lambda_{\mathrm{L}}=1.0$ ). b) Series resonance (power system data in Section 3.2: $X_{S}=0.154 \mathrm{pu}, R_{L}=1.464 \mathrm{pu}, \lambda_{L}=0.95,\left|\underline{Z}_{p 1}\right|=30.788 \mathrm{pu}, \lambda_{P}=0.95$ and threephase load model LM1).

To illustrate the above study, Fig. 8 shows $\left|\underline{Z}_{A A k}\right|_{N},\left|\underline{Y}_{A A k}\right|_{N},\left|\underline{Y}_{A A k, \text { apx }}\right|_{N}$ and $\left|\underline{\Delta}_{k}\right|$ for the power systems presented in the laboratory tests of Sections 3.1 and 3.2, and the analytical results of the resonances (22) for these systems are

- Parallel resonance: $k_{r, a}=4.94$ and $7.05\left(\tau_{1}=0\right.$ and $d_{C}=1.0$ and 0.5 , respectively $)$ and $k_{r, \mathrm{a}}=5.13$ and $7.33\left(\tau_{1}=6.0 \%\right.$ and $d_{C}=1.0$ and 0.5 , respectively). 
- Series resonance: $k_{r, \text { a }}=4.95$ and $7.03\left(\tau_{1}=0\right.$ and $d_{C}=1.0$ and 0.5 , respectively) and $k_{r, \mathrm{a}}=6.16$ and $8.74\left(\tau_{1}=7.9 \%\right.$ and $d_{C}=1.0$ and 0.5 , respectively).

From these results, it is seen that

- As the variable $z_{P}=30.788 / 0.154=199.9>20$, the numerical results obtained from $\left|\underline{Y}_{A A k, \text { apx }}\right|_{\mathrm{N}}$ are similar to those obtained from $\left|\underline{Y}_{A A k}\right|_{\mathrm{N}}$, and $k_{s, \mathrm{n}} \approx k_{s, \text { napx }}$.

- The harmonic of the $\left|\underline{Z}_{A A k}\right|_{\mathrm{N}}$ and $\left|\underline{Y}_{A A k \text {, apx }}\right|_{\mathrm{N}}$ (and therefore $\left|\underline{Y}_{A A k}\right|_{\mathrm{N}}$ ) maximum values nearly coincides with the harmonic of the $\left|\underline{\Delta}_{k}\right|$ minimum value, $k_{r, \Delta} \approx k_{p, \mathrm{n}}$ and $k_{r, \Delta} \approx k_{s, \text { napx }}$, and that (22) provides the harmonic of the parallel and series resonance correctly, i.e. $k_{r, \mathrm{a}} \approx k_{p, \mathrm{n}}$ and $k_{r, \mathrm{a}} \approx k_{s \text {, napx. }}$.

- $\quad$ Although the resistances $R_{S}$ and $R_{1}$ of the supply system and the Steinmetz circuit inductor are neglected in the analytical study [i.e., $\underline{Z}_{S k} \approx j k \cdot X_{S}$ and $\underline{Z}_{1 k} \approx j \cdot k \cdot X_{1}$ in (14)], the results are in good agreement with the experimental measurements in Sections 3.1 and 3.2, i.e. $k_{r \text {, a }} \approx k_{p}$, meas and $k_{r, \mathrm{a}} \approx k_{s, \text { meas. }}$. However, the magnitude values obtained numerically are greater than the experimental measurements (e.g., $\left|\underline{Z}_{A A k}\right|=X_{S} \cdot\left|\underline{Z}_{A A k}\right|_{\mathrm{N}}=0.049 \cdot 33.03=1.62 \mathrm{pu}$ for $k_{p, \mathrm{n}}=7.04$ in the $\tau_{1}=0 \%$ and $d_{C}=0.5$ plot of Fig. 8 and $\left|\underline{Z}_{A A k}\right| \approx 1.1$ pu for $k_{p \text {, meas }}=7.2$ in Fig. 5 or $\left|\underline{Y}_{A A k}\right|=\left|\underline{Y}_{A A k}\right|_{\mathrm{N}} / X_{S}=0.73 / 0.154=4.74 \mathrm{pu}$ for $k_{\mathrm{s}, \mathrm{n}}=7.09$ in the $\tau_{1}=0 \%$ and $d_{C}=0.5$ plot of Fig. 8 and $\left|\underline{Y}_{A A k}\right| \approx 2.1$ pu for $k_{p \text {, meas }}=7.2$ in Fig. 7).

- $\quad$ The influence of the resistance $R_{1}$ on Steinmetz circuit design (3) shifts the parallel and series resonance to higher frequencies. This was also experimentally verified in the laboratory test of Section 3.

Fig. 9 compares $k_{r, a}$, with $k_{p, \mathrm{n}}$ and $k_{s, \mathrm{n}}$. Considering the validity range of the involved variables, the values leading to the largest differences are used. It can be observed that $k_{r \text {, a }}$ provides the correct harmonic of the parallel and series resonance. The largest differences obtained are below $10 \%$ and correspond to $k_{s, n}$ when $\mathrm{z}_{P}=20$, which is the lowest acceptable $\mathrm{z}_{P}$ value to apply the $k_{r \text {, a }}$ analytical expression. Although only the linear load model LM1 is considered in the calculations, it is verified that the above conclusions are true for the other three-phase load models.

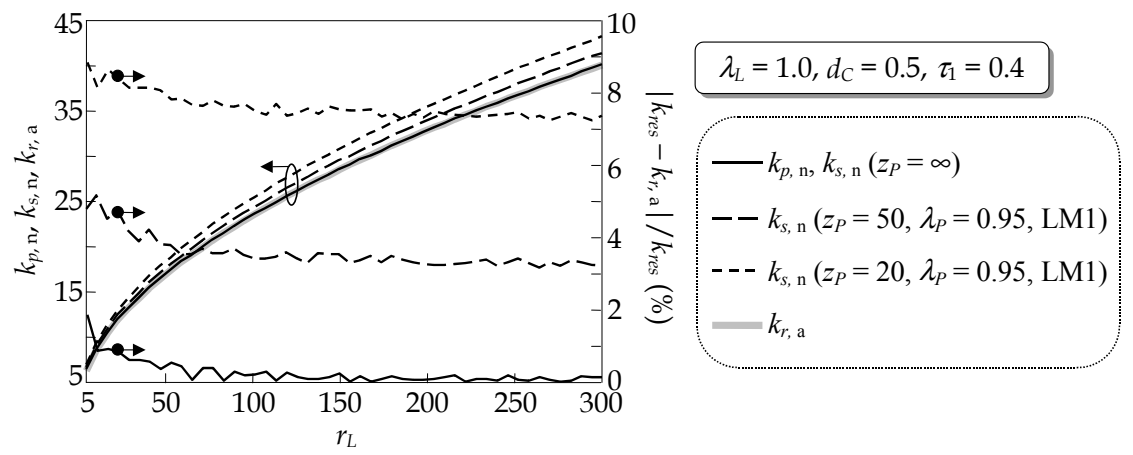

Fig. 9. Comparison between $k_{r e s}$ and $k_{r, \mathrm{a}}\left(k_{r e s}=k_{p, \mathrm{n}}\right.$ or $\left.k_{s, \mathrm{n}}\right)$.

The previous research unifies the study of the parallel and series resonance, providing an expression unique to their location. This expression is the same as in the series resonance case (Sainz et al., 2007), but substantially improves those obtained in the parallel resonance case (Sainz et al., in press). Moreover, the Steinmetz circuit inductor resistance is considered 
in the analytical location of the resonances, making a contribution to previous studies. This resistance, as well as damping the impedance values, shifts the resonance frequencies because it influences Steinmetz circuit design (i.e., the determination of the Steinmetz circuit reactances).

\section{Sensitivity analysis of power system harmonic response}

A sensitivity analysis of all variables involved in location of the parallel and series resonance is performed from (22). Thus, considering the range of the variables, Fig. 10 shows the contour plots of the harmonics where the parallel and series resonance is located. These harmonics are calculated from the expression of $k_{r, \text { a }}(22)$, and the $\tau_{1}$ range is fixed from (4) considering the $\lambda_{L}$ value. From Fig. 10, it can be noted that

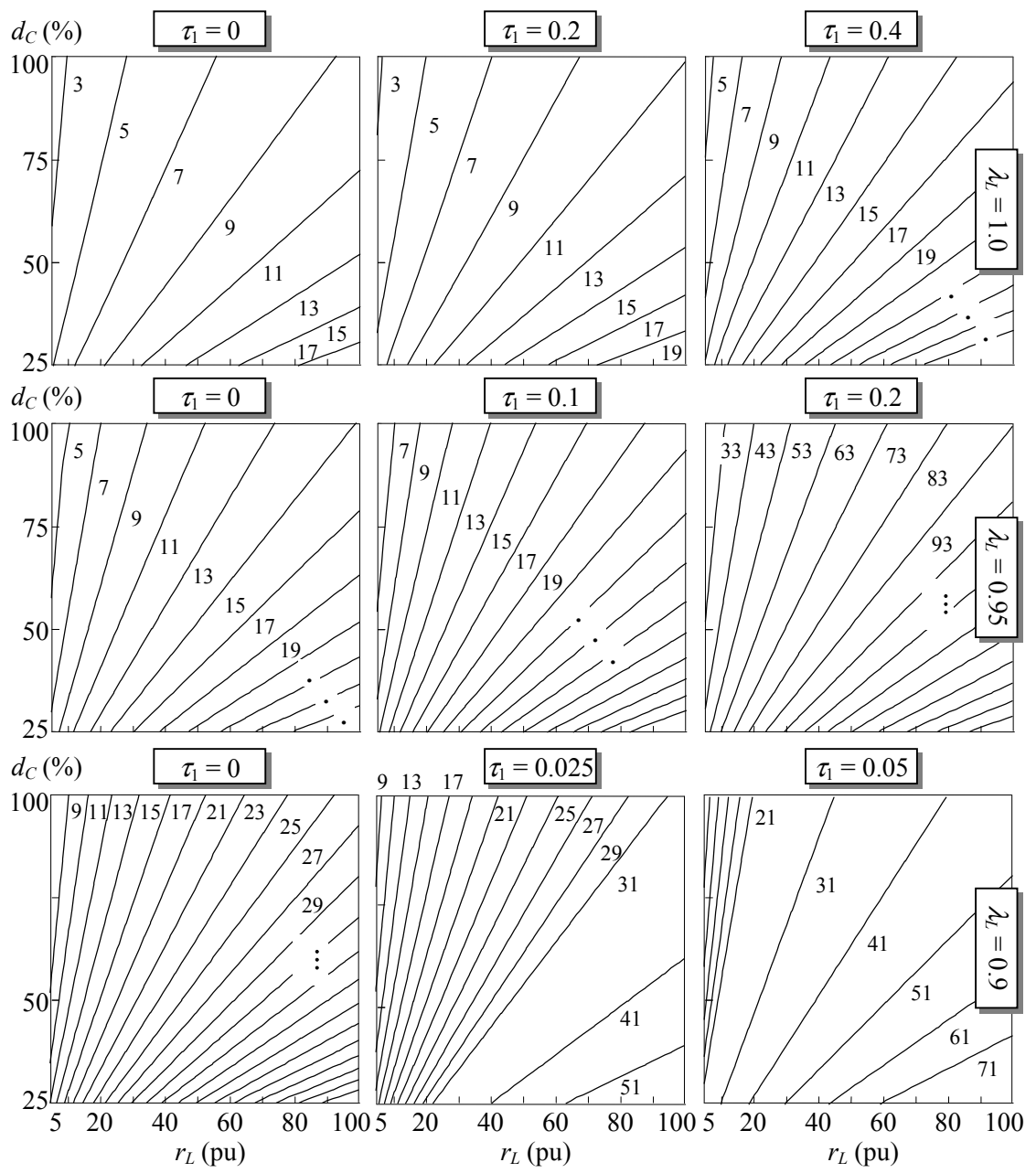

Fig. 10. Contour plots of $k_{r, \mathrm{a}}$. 
- The resonant behavior of the Steinmetz circuit with power system reactors occurs in a range of relatively large harmonics.

- The resonances are located in the low-order harmonics only if the displacement power factor of the single-phase load impedance is close to the unity value (i.e., $\lambda_{L} \approx 1$ ) and this impedance is small in comparison with the supply system reactances (i.e., small $r_{L}$ ratios). The former condition is common but, considering that $r_{L}=\lambda_{L} \cdot S_{S} / S_{L}$ (Sainz et al., 2009a), the latter only occurs in weak power systems where the short-circuit power at the PCC bus, $S_{S}$, is low compared to the apparent power of the single-phase load, $S_{L}$.

- The resonances are shifted to high-order harmonics if the $\tau_{1}$ ratio of the Steinmetz circuit inductor is far from the zero value, i.e. its displacement power factor $\lambda_{1}$ is far from the unity value. It is also true if the Steinmetz circuit capacitor degrades, i.e. the Steinmetz circuit suffers capacitor loss and $d_{C}$ is also far from the unity value.

\section{Examples}

For the sake of illustration, two different implementations of the $k_{r \text {, a }}$ expression, (22), are developed. In the first, the analytical study in Section 4 is validated from laboratory measurements. Several experimental tests were made to check the usefulness of the $k_{r \text {, a }}$ expression in locating the parallel and series resonance. In the second, this expression is applied to locate the harmonic resonance of several power systems with a Steinmetz circuit in the literature.

\subsection{Experimental measurements of power system harmonic response}

To validate the analytical study, measurements were made in two downscaled laboratory systems corresponding to the networks of Fig. 4 (parallel resonance) and Fig. 6 (series resonance). The frequency response measurements were made with a $4.5 \mathrm{kVA}$ AC ELGAR Smartwave Switching Amplifier as the power source, which can generate sinusoidal waveforms of arbitrary frequencies (between $40 \mathrm{~Hz}$ and $5000 \mathrm{~Hz}$ ) and a YOKOGAWA DL $708 \mathrm{E}$ digital scope as the measurement device. From the results shown in the next Sections, it must be noted that (22) provides acceptable results. Although experimental tests considering the inductor resistance $\left(R_{1} \approx 0.1342 \mathrm{pu}\right)$ are not shown, they provide similar results.

\subsubsection{Experimental measurements of the parallel resonance}

The harmonic response of the network in Fig. 4 was measured in the laboratory for two cases with the following system data $\left(U_{\mathrm{B}}=100 \mathrm{~V}\right.$ and $\left.S_{\mathrm{B}}=500 \mathrm{VA}\right)$ :

- $\quad$ Case 1 (studied in Section 3.1):

- $\quad$ Supply system: $\underline{Z}_{S 1}=0.022+j 0.049$ pu.

- $\quad$ Railroad substation: $R_{L}=1.341 \mathrm{pu}, \lambda_{L}=1.0$.

- External balancing equipment: $X_{1, \text { apx }}=2.323 \mathrm{pu}$ and $X_{2, \text { apx }}=2.323 \mathrm{pu}$ [neglecting the inductor resistance, (1)] and $d_{C}=1.0,0.75,0.5$ and 0.25 .

- Case 2: System data of Case 1 except the single-phase load fundamental displacement factor of the railroad substation, which becomes $\lambda_{L}=0.95$. The Steinmetz circuit reactances also change, i.e. $X_{1, \text { apx }}=1.640 \mathrm{pu}$ and $X_{2 \text {, apx }}=5.975 \mathrm{pu}(1)$.

Fig. 11a compares the parallel resonance measured in the experimental tests with those obtained from (22). In order to analytically characterize the resonance, the variable values 
corresponding to the above data are $r_{L}=27.4, \lambda_{L}=1$ and 0.95 (Cases 1 and 2, respectively) and $\tau_{1}=0$.

\subsubsection{Experimental measurements of the series resonance}

The harmonic response of the network in Fig. 6 was measured in the laboratory for two cases with the following system data $\left(U_{\mathrm{B}}=100 \mathrm{~V}\right.$ and $\left.S_{\mathrm{B}}=500 \mathrm{VA}\right)$ :

- $\quad$ Case 1:

- $\quad$ Supply system: $\underline{Z}_{S 1}=0.076+j 0.154 \mathrm{pu}$.

- $\quad$ Railroad substation: $R_{L}=1.464 \mathrm{pu}, \lambda_{L}=1.0$.

- External balancing equipment: $X_{1, \text { apr }}=2.536 \mathrm{pu}$ and $X_{2, \text { apr }}=2.536 \mathrm{pu}$ [neglecting the inductor resistance, $(1)]$ and $d_{C}=1.0,0.75,0.5$ and 0.25 .

- $\quad$ Three-phase load: Grounded wye series R-L impedances with $\left|\underline{Z}_{P 1}\right|=30.788 \mathrm{pu}$ and $\lambda_{P}=0.95$ are connected, i.e. the three-phase load model LM1 in (Task force on Harmonic Modeling and Simulation, 2003).

- Case 2 (studied in Section 3.2): System data of Case 1 except the single-phase load fundamental displacement factor of the railroad substation, which becomes $\lambda_{L}=0.95$. The Steinmetz circuit reactances also change, i.e. $X_{1 \text {, apr }}=1.790 \mathrm{pu}$ and $X_{2 \text {, apr }}=6.523 \mathrm{pu}$ (1).

Fig. $11 \mathrm{~b}$ compares the series resonance measured in the experimental tests with those obtained from (22). In order to analytically characterize the resonance, the variable values corresponding to these data are $r_{L}=9.51, \lambda_{L}=1$ and 0.95 (Cases 1 and 2, respectively) and $\tau_{1}=0$.

(a)

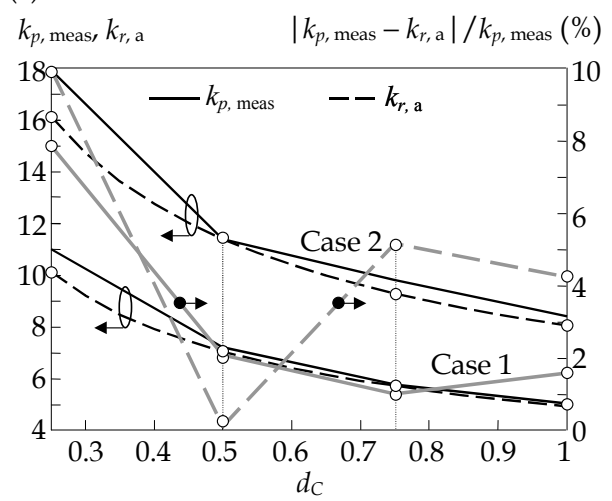

(b)

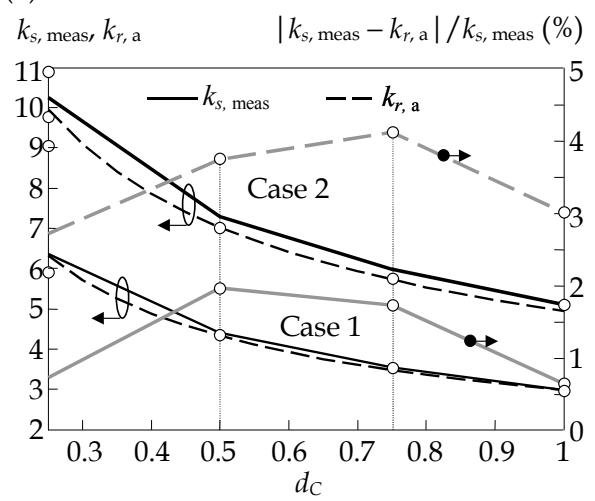

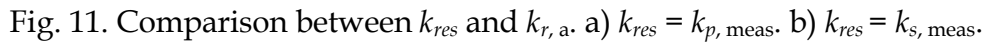

\subsection{Harmonic resonance location in several power systems}

This section briefly describes several works in the literature on the Steinmetz circuit in power systems, and determines the harmonic of the resonance produced by the presence of this circuit from (22). This allows interpreting the results in the works and predicting the harmonic behavior of the studied power systems.

In (ABB Power Transmission, n.d.), an extensive railway network for coal haulage in East Central Queensland is presented and the installation of nine SVCs in the $132 \mathrm{kV}$ grid to 
achieve dynamic load balancing is analyzed. The traction load is supplied from single-phase $132 / 50 \mathrm{kV}$ transformers at each supply substation providing a $25 \mathrm{kV}$ catenary voltage from $50 / 25 \mathrm{kV}$ autotransformers at intervals along the track. The short-circuit power $S_{S}$ at $132 \mathrm{kV}$ bus is below 300 MVA while traction loads may reach short duration peaks of $S_{L}=20$ to 40 MVA. A total of 28 single-phase harmonic filters for $50 \mathrm{kV}$ tuned to the $3^{\text {rd }}, 5^{\text {th }}$ and $7^{\text {th }}$ harmonics were installed in the substations to prevent harmonics generated in the locomotive thyristor drives from being injected into the $132 \mathrm{kV}$ power system. The harmonic impact of the Steinmetz circuit installation on this traction system can be examined from (22). Considering $\tau_{1}=0, d_{C}=1$ and the displacement power factor $\lambda_{L}$ of the traction load close to the unity value, the ratio $r_{L}=R_{L} / X_{S}=\lambda_{L} \cdot S_{S} / S_{L}$ is between 15 to $7.5\left(S_{L}=20\right.$ to 40 , respectively) and the resonance is located at the harmonics $k_{r \text {, a }}=3.7$ to 2.68 . It is interesting to note that the Steinmetz circuit connection could cause parallel and series resonances close to the $3^{\text {rd }}$ harmonic, damaging harmonic power quality. If the displacement power factor was below unity value (e.g., $\lambda_{L}=0.95$ ), the resonance would shift to $k_{r \text {, a }}=5.93$ to 4.36 $\left(S_{L}=20\right.$ to 40 , respectively) worsening the harmonic problem. In conclusion, it is not advisable to use the Steinmetz circuit to balance the traction load currents consumed in this installation. However, since the short-circuit power can be below $300 \mathrm{MVA}$ and the transformer short-circuit impedances are not considered in the study, the ratio $r_{L}$ values can be lower than the previous ones and the resonance can be below the $3^{\text {rd }}$ harmonic (see Fig. 10) avoiding harmonic problems.

In (Barnes \& Wong, 1991), an unbalance and harmonic study carried out for the Channel Tunnel $25 \mathrm{kV}$ railway system supplied from the UK and French 400/225/132 kV grid systems is presented. On the UK side, the PCC between the traction load and the tunnel auxiliary load is at the Folkestone $132 \mathrm{kV}$ busbar with a minimum short-circuit power $S_{S}$ equal to $800 \mathrm{MVA}$. On the French side, the PCC between the traction load, the auxiliary load and other consumers is at the Mandarins $400 \mathrm{kV}$ busbar with a minimum short-circuit power $S_{S}$ equal to $11700 \mathrm{MVA}$. The traction loads range from $S_{L}=0$ to $75 \mathrm{MVA}$ with a displacement power factor $\lambda_{L}=0.93$. Steinmetz circuit is located on the UK side with fastacting thyristor-controlled reactors and capacitors, which enable the balancing equipment output to vary with the load pattern. Moreover, harmonic studies based on the harmonic spectrum measured in the catenaries of the British Rail network and provided by continental locomotive manufacturers were conducted to analyze the harmonic filter installation. They revealed that the harmonic limits on the French side are within specification limits and no filters are required while, on the UK side, these limits are exceeded and harmonic filters must be installed to reduce harmonic distortion to acceptable levels. These studies can be complemented with harmonic resonance location in the Steinmetz circuit. Thus, considering $\tau_{1}=0, d_{C}=1$ and the maximum traction load (i.e., $\left.S_{L}=75 \mathrm{MVA}\right)$, the ratio $r_{L}=R_{L} / X_{S}=\lambda_{L} \cdot S_{S} / S_{L}$ is 145.08 and 9.92 and the resonance is located at harmonics $k_{r, a}=21.6$ and 6.0 on the French and UK side, respectively. This resonance is shifted to higher harmonics if the traction load is lower. The auxiliary loads and other consumers are not considered in the location of the resonances because their impedance is large enough (i.e., $\left.z_{P}>20\right)$.

In (Arendse \& Atkinson-Hope, 2010), the design of the Steinmetz circuit in unbalanced and distorted power supplies is studied from a downscaled laboratory system such as that in Fig. 3. The system data are $\underline{Z}_{S 1}=0.0087+j 0.00079 \Omega, R_{L}=4.84 \Omega, \lambda_{L}=1.0, \tau_{1}=0, d_{C}=1.0$ and a three-phase Variable Speed Drive (VSD) of $24 \mathrm{kVA}$ rated power is used as a harmonic 
source. A three-phase linear load with $\left|\underline{Z}_{P 1}\right|=9.802 \Omega$ and $\lambda_{P}=0.81$ (load model LM1) is also connected. The study shows that there is no harmonic problem in the system and that voltage distortion is below $0.05 \%$ [Table 7 in (Arendse \& Atkinson-Hope, 2010)]. This can be analyzed from (22) because, considering that $r_{L}=4.84 / 0.00079=6127$ and $z_{P}=9.802 / 0.00079=12408$ (i.e., the three-phase linear load influence is negligible), the parallel resonance "observed" from the VSD is located at $k_{r, \mathrm{a}}=72.9$.

\section{Conclusion}

In this chapter, the analytical study conducted in previous works on the parallel and series resonance in power systems with a Steinmetz circuit is unified and an expression unique to the location of both resonances is provided, which substantially improves those proposed in earlier works on the parallel resonance. This expression considers not only the impact of capacitor degradation on the resonance but also the resistance of the Steinmetz circuit inductor, which is another contribution to previous studies.

The sensitivity analysis reveals that the resonances mainly depend on the power system inductors and the single-phase load of the Steinmetz circuit. However, capacitor bank degradation and the $\mathrm{R} / \mathrm{X}$ ratio of the Steinmetz circuit inductor can also strongly influence the resonance. Broadly speaking, Steinmtez circuit resonances with power system reactors appear at high-order harmonics. They only occur at low-order harmonics if the single-phase load impedance is small in comparison with the supply system reactance (i.e., in weak power systems) and the single-phase load power displacement factor is close to the unity value. The study also shows that the capacitor bank degradation and the resistance of the Steinmetz circuit inductor shift the resonance to higher harmonics. The analytical study results are validated with experimental measurements in a downscaled laboratory system and the study is applied to analyze several power systems with a Steinmetz circuit in the literature. Measurements in actual ac traction systems will be necessary to fully confirm these results.

Future research should focus on the power system harmonic response "observed" from the railroad substation. The framework developed in the previous research and completed in this Chapter must make it possible to obtain analytical expressions to locate resonances from the substation.

\section{Acknowledgment}

This work is supported by grant DPI2010-15448.

\section{References}

ABB Power Transmission (n.d.). Multiple SVC installations for traction load balancing in Central Queensland. In: Pamphlet A02-0134, 26/02/2011, Available from $<$ http://www.abb.com/>.

Arendse, C. \& Atkinson-Hope, G. (2010). Design of a Steinmetz symmetrizer and application in unbalanced network. Proceedings of the $45^{\text {th }}$ International Universities Power Engineering Conference (UPEC), pp. 1-6, 2010. 
Barnes, R. \& Wong, K. T. (1991). Unbalance and harmonic studies for the Channel Tunnel railway system. IEE Proceedings B, Electric Power Applications, Vol. 138, No. 2, 1991, pp. $41-50$.

Capasso, A. (1998). The power quality concern in railway electrification studies. Proceedings of $8^{\text {th }}$ IEEE Int. Conf. on Harmonics and Quality of Power (ICHQP), pp. 647-652, 1998.

Caro, M., Sainz, L. \& Pedra, J. (2006). Study of the power system harmonic response in the presence of the Steinmetz circuit. Electric Power Systems Research, Vol. 76, No. 12, August 2006, pp. 1055-1063.

Chen, T-H. (1994). Criteria to estimate the voltage unbalances due to high-speed railway demands. IEEE Transactions on Power Systems, Vol. 9, No. 3, August 1994, pp. 16721678 .

Chen, T-H. \& Kuo, H-Y. (1995). Analysis on the voltage unbalance due to high-speed railway demands. Proceedings of the International Conference on Energy Managment and Power Delivery, pp. 657-661, 1995.

Chicco, G., Chindris, M., Cziker, A., Postolache, P. \& Toader, C. (2009). Analysis of the Steinmetz compensation circuit with distorted waveforms through symmetrical component-based indicators. Proceedings of the IEEE Bucharest Power Tech Conference 2009, pp. 1-6, 2009.

Chindris, M., Cziker, A., Stefanescu, A. S. \& Sainz, L. (2002). Fuzzy logic controller for Steinmetz circuitry with variable reactive elements. Proceedings of $8^{\text {th }}$ International Conference OPTIM 2002, Proc. 1G.3, pp. 233-238, 2002.

Czarnecki, L. S. (1989). Reactive and unbalanced currents compensation in three-phase asymmetrical circuits under non-sinusoidal conditions. IEEE Transactions on Instrumentation and measurement, June 1989, Vol. 38, No. 3, pp. 754-759.

Czarnecki, L. S. (1992). Minimization of unbalanced and reactive currents in three-phase asymmetrical circuits with non-sinusoidal voltage. Proceedings IEE, Vol. 139, Pt. B., No. 4, July 1992, pp. 347-354.

Hill, R. J. (1994). Electric railway traction. Part3: Traction power supplies. Power Engineering Journal, Vol. 8, No. 6, 1994, pp. 275-286.

Howroyd, D. C. (1989). Public supply disturbances from AC traction. Proceedings of the International Conference on Main Line Railway Electrification, pp. 260-264, 1989.

IEC 61000-3-6, Part 3-6: Limits - Assessment of emission limits for the connection of distorting installations to MV, HV and EHV power systems, 2008-02.

Jordi, O., Sainz, L. \& Chindris, M. (2002). Steinmetz system design under unbalanced conditions. European Transactions on Electrical Power, Vol. 12, No.4, July/August 2002, pp. 283-290.

Lee, S.Y. \& Wu, C.J. (1993). On-line reactive power compensation schemes for unbalanced three-phase four wire distribution feeders. IEEE Transactions on Power Delivery, Vol. 8, No. 4, October 1993, pp. 1958-1965.

Marczewski, J. J. (1999). IEEE working group on system and equipment considerations for traction. Utility interconnection issues. Proceedings of IEEE Power Engineering Society Summer Meeting, Vol. 1, pp. 439-444, 1999.

Mayer, D. Kropik, P. (2005). New approach to symmetrization of three-phase networks. Journal of Electrical Engineering, 2005, Vol. 56, No. 5-6, pp. 156-161. 
Qingzhu, W., Mingli, W., Jianye, C. \& Guipping, Z. (2010). Optimal balancing of large single-phase traction load. Proceedings of the IET Conference on Railway Traction Systems (RTS 2010), pp. 1-6, 2010.

Qingzhu, W., Mingli, W., Jianye, C. \& Guipping, Z. (2010). Model for optimal balancing single-phase traction load based on the Steinmetz's method. Proceedings of the IEEE Energy Conversion Congress an Exposition (ECCE), pp. 1565-1569, 2010.

Sainz, L., Caro, M. \& Pedra, J. (2004). Study of electric system harmonic response. IEEE Transactions on Power Delivery, Vol. 19, No. 2, April 2004, pp. 868-874.

Sainz, L., Pedra, J. \& Caro, M. (2005). Steinmetz circuit influence on the electric system harmonic response. IEEE Transactions on Power Delivery, Vol. 20, No. 2, April 2005, pp. 1143-1156.

Sainz, L., Pedra, J. \& Caro, M. (2007). Influence of the Steinmetz circuit capacitor failure on the electric system harmonic response. IEEE Transactions on Power Delivery, Vol. 22, No. 2, April 2007, pp. 960-967.

Sainz, L., Pedra, J. \& Caro, M. (2009). Background voltage distortion influence on the power electric systems in the presence of the Steinmetz circuit. Electric Power Systems Research, Vol. 79, No. 1, January 2009, pp. 161-169.

Sainz, L., Caro, M. \& Caro, E. (2009). Analytical study on the series resonance in power systems with the Steinmetz circuit. IEEE Transactions on Power Delivery, Vol. 24, No. 4, October 2009, pp. 2090-2098.

Sainz, L., Caro, M., Caro, E. (in press). Influence of Steinmetz Circuit Capacitor Degradation on Series Resonance of Networks. European Transactions on Electrical Power, in press (DOI: 10.1002/etep.514).

Sainz, L. \& Riera, S. (submitted for publication). Study of the Steinmetz circuit design. Power Systems Research.

Task Force on Harmonics Modeling and Simulations. Modeling and simulation of the propagation of harmonics in electric power networks. Part I: Concepts, models and simulation techniques. IEEE Transactions on Power Delivery, Vol. 11, No. 1, January 1996, pp. 452-465.

Task Force on Harmonic Modeling and Simulation. Impact of aggregate linear load modeling on harmonic analysis: A comparison of common practice and analytical models. IEEE Transactions on Power Delivery, Vol. 18, No. 2, April 2003, pp. 625-630. 


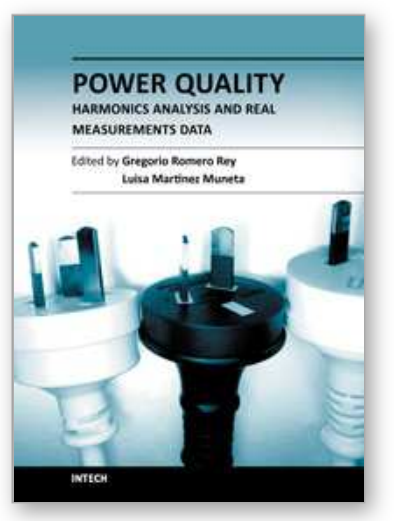

\author{
Power Quality Harmonics Analysis and Real Measurements Data \\ Edited by Prof. Gregorio Romero
}

ISBN 978-953-307-335-4

Hard cover, 278 pages

Publisher InTech

Published online 23, November, 2011

Published in print edition November, 2011

Nowadays, the increasing use of power electronics equipment origins important distortions. The perfect AC power systems are a pure sinusoidal wave, both voltage and current, but the ever-increasing existence of nonlinear loads modify the characteristics of voltage and current from the ideal sinusoidal wave. This deviation from the ideal wave is reflected by the harmonics and, although its effects vary depending on the type of load, it affects the efficiency of an electrical system and can cause considerable damage to the systems and infrastructures. Ensuring optimal power quality after a good design and devices means productivity, efficiency, competitiveness and profitability. Nevertheless, nobody can assure the optimal power quality when there is a good design if the correct testing and working process from the obtained data is not properly assured at every instant; this entails processing the real data correctly. In this book the reader will be introduced to the harmonics analysis from the real measurement data and to the study of different industrial environments and electronic devices.

\title{
How to reference
}

In order to correctly reference this scholarly work, feel free to copy and paste the following:

Luis Sainz, Eduardo Caro and Sara Riera (2011). Characterization of Harmonic Resonances in the Presence of the Steinmetz Circuit in Power Systems, Power Quality Harmonics Analysis and Real Measurements Data, Prof. Gregorio Romero (Ed.), ISBN: 978-953-307-335-4, InTech, Available from:

http://www.intechopen.com/books/power-quality-harmonics-analysis-and-real-measurementsdata/characterization-of-harmonic-resonances-in-the-presence-of-the-steinmetz-circuit-in-power-systems

\section{INTECH}

open science | open minds

\section{InTech Europe}

University Campus STeP Ri

Slavka Krautzeka 83/A

51000 Rijeka, Croatia

Phone: +385 (51) 770447

Fax: +385 (51) 686166

www.intechopen.com

\section{InTech China}

Unit 405, Office Block, Hotel Equatorial Shanghai

No.65, Yan An Road (West), Shanghai, 200040, China 中国上海市延安西路65号上海国际贵都大饭店办公楼 405 单元

Phone: +86-21-62489820

Fax: +86-21-62489821 
(C) 2011 The Author(s). Licensee IntechOpen. This is an open access article distributed under the terms of the Creative Commons Attribution 3.0 License, which permits unrestricted use, distribution, and reproduction in any medium, provided the original work is properly cited. 